\title{
PUNCHING OF REINFORCED CONCRETE FLAT SLABS - RATIONAL USE OF HIGH STRENGTH CONCRETE
}

\author{
Micael M.G. Inácio ${ }^{1}$, Massimo Lapi ${ }^{2}$, Antonio Pinho Ramos ${ }^{3}$ \\ ${ }^{1}$ PhD, Department of Civil Engineering, Faculdade de Ciências e Tecnologia da Universidade \\ NOVA de Lisboa, Caparica, Portugal.micael.inacio@engenheiros.pt \\ ${ }^{2}$ PhD Student, DICEA, Università degli Studi di Firenze, Via di Santa Marta n.3, 50139, Firenze, \\ Italy.massimo.lapi@unifi.it \\ ${ }^{3}$ Professor, CERIS, ICIST, Department of Civil Engineering, Faculdade de Ciências e Tecnologia da \\ Universidade NOVA de Lisboa, Caparica, Portugal. ampr@fct.unl.pt
}

\begin{abstract}
This paper deals with punching of reinforced high strength concrete (HSC) flat slabs. Despite the use of HSC increased significantly in the last years, the experimental research on punching behavior of HSC slabs is still limited. Furthermore, most of this past research adopted concrete compressive strength lower than $90 \mathrm{MPa}$. In a previous work by this research group three specimens with concrete compressive strength around $120 \mathrm{MPa}$ and one with normal strength concrete (NSC) were tested. The present work represents the continuation of the previous activity and it is focused on the rational use of HSC. Four specimens with HSC and one of NSC were tested under monotonic vertical loading. The HSC was placed only in the slab-column connection region and it was limited to a thin layer in the compressive zone, in order to have a more economical and sustainable solution. This rational use of the HSC showed excellent results in terms of punching strength. Limiting the HSC to a thin layer in the compressive zone resulted in an almost equal punching strength to that obtained with the slab entirely casted in HSC.
\end{abstract}

\section{INTRODUCTION}

In the last years the use of high strength concrete (HSC) increased significantly. There are several examples of buildings or bridges in which HSC is present all over the world [1-5]. An important contribute to the development of the HSC was provided in Chicago. From the 1960s to the 1970s the concrete strength used in Chicago for the construction of high rise buildings passed from 15-20 MPa to 45-60 MPa [2]. In 1960 the Washington State Highway Department specified $41 \mathrm{MPa}$ for concrete prestressed girders and one year later in Seattle concrete strengths of $48 \mathrm{MPa}$, while $55 \mathrm{MPa}$ were specified respectively for the monorail track girders and for the concrete piles of the Seattle Port [6]. The rapid increase of the attainable compressive strength showed in the 1960s was mainly due to the spread of chemical and mineral admixtures [7] that allowed for reducing the water content in the concrete.

The definition of HSC has changed over the years, during the 1950s a concrete with a compressive strength higher than $34 \mathrm{MPa}$ was considered by the American Concrete Institute (ACl) as HSC [8]. In 1984 the $\mathrm{ACl}$ defined the HSC with a concrete strength higher than $41 \mathrm{MPa}$, this value remained valid until 1997 when the minimum strength to be considered HSC was set 
equal to $55 \mathrm{MPa}$ [9]. Currently, $\mathrm{ACl} 318-19$ [10] does not include any definition of HSC, however in the commentary the use of other formulae for the calculation of the elasticity modulus is suggested when the concrete compressive strength is higher than $55 \mathrm{MPa}$. Nowadays there is no definition of HSC in European codes, however in both Eurocode 2004 [11] and Model Code 2010 [12] measures and formulae change when the concrete strength is greater than $\mathrm{C} 50 / 60$. For this reason, $50 \mathrm{MPa}$ could be assumed as the minimum strength for a concrete to be considered an HSC.

With regards to punching of reinforced concrete flat slabs there are few experimental campaigns dealing with HSC. In 1991 Marzouk and Hussein [13] studied the punching behavior of HSC flat slabs by testing 17 specimens, two of these with normal strength concrete (NSC) for reference. The $1700 \mathrm{~mm} \times 1700 \mathrm{~mm}$ square slabs were simply supported along the perimeter and they were axially loaded through a column stub. The used HSC compressive strength varied from $66 \mathrm{MPa}$ to $80 \mathrm{MPa}$. Only two specimens, with low reinforcement ratio, failed by flexure while the others failed by punching. The authors observed that HSC slabs exhibit a more brittle failure than NSC slabs. In 1993 Regan et al. [14] and Ramdane [15] tested 18 circular slabs with a diameter of $1700 \mathrm{~mm}$ and a thickness of $125 \mathrm{~mm}$. However, considering just the HSC slabs that failed by punching the available tests are only 6 . The authors observed that the slab deformation outside the supported zone could be assimilated to a rigid body rotation. The slab rotation at failure decreased as the longitudinal reinforcement ratio increased. Also in 1993 Tomaszewicz [16] performed an extensive experimental campaign consisting in 19 square slabs, 13 in normal weight concrete and 6 in light weight concrete. The slab thickness varied from $120 \mathrm{~mm}$ to $320 \mathrm{~mm}$ and the longitudinal reinforcement ratio was fixed between $1.49 \%$ and $2.62 \%$. The concrete compressive strength varied from $64 \mathrm{MPa}$ to $112 \mathrm{MPa}$. The author observed that in the case of HSC, simple extending of existing design methods can lead to an overestimation of the punching strength.

The present research represents the continuation of a previous work performed by Inácio et al. [17] that consisted of an experimental campaign including three HSC slabs and one NSC slab. The authors highlighted that as the concrete compressive strength increases from $36 \mathrm{MPa}$ to $130 \mathrm{MPa}$ the punching capacity increases $42 \%$, for longitudinal reinforcement ratios of $1.25 \%$. The present paper is focused on the rational use of the HSC to improve the punching strength of reinforced concrete flat slabs, because since being a more costly material, when compared with NSC, the use of HSC should be optimized. With that aim in mind, the objective was to use only the HSC in localized areas at the slab-column connection, being the rest of the slab cast with NSC. The zone casted with HSC was not only limited in plan, but also in height, being the HSC only used in a thin layer in the compressive zone. The reasoning to this assumption was the works of Faria et al. [18] and Mamede et al. [19] that suggested that the compressive strength was more relevant to increase the punching capacity, than the concrete tensile strength. This way it was possible to minimize the economic impact of using HSC and enhance its competitiveness. 
The first example of rational use of HSC applied to flat slabs was provided by Hallgren and Kinnunen [20] [21], where the concrete compressive strength of NSC and HSC were equal to 25 $\mathrm{MPa}$ and $95 \mathrm{MPa}$ respectively. The authors highlighted that the test slab with HSC placed locally above the column and with NSC cast around the HSC portion provided almost the same results of slabs made completely with HSC. The punching strength resulted about $60 \%$ higher than that of the identical NSC slabs. In 2015 Zohrevand et al. [22] studied the partial use of HSC to enhance the punching strength of flat-slabs. The authors developed three specimen configurations, the full use of NSC or HSC, the combined use of full-depth HSC in the column vicinity and NSC outside, and the combined use of half-depth HSC in column vicinity in the tension zone and NSC outside. The compressive strength of the HSC varied from $129 \mathrm{MPa}$ to $151 \mathrm{MPa}$ while the NSC was about $45 \mathrm{MPa}$. The punching capacity of a slab made completely in HSC resulted more than 3 times that provided by the slab in NSC. The use of full-depth HSC in the column vicinity allowed for shifting the punching cone outside the strengthened zone, as in case of shear reinforcement, increasing the punching shear area and enhancing the punching strength. Conversely the half-depth application of HSC in column vicinity in tension zone did not significantly increase the punching strength of the slab. In the latter case the critical crack passed outside the strengthened zone, affecting only NSC.

Differently to Zohrevand et al. [22] the use of HSC in compression zone is preferred to the tension zone. This choice is supported by several considerations. From a mechanical point of view the HSC in compression zone enhances the stiffness and the flexural capacity of the slab allowing for increasing the punching strength. In general the presence of HSC in column vicinity increases the interlocking strength, however when the HSC is used in tension zone the critical crack could deviate affecting only the NSC, as shown by Zohrevand et al. [22]. Conversely when the HSC is applied in the compressive zone the critical crack is obligated to pass through this layer or alternative the punching cone is shifted outside the strengthened zone. In both cases the punching strength is significantly increased. Actually, for concrete compressive strength $f_{c m}>60 \mathrm{MPa}$ the beneficial effect provided by the presence of HSC can be partially lost by the lower roughness of the critical crack due to the failure of the aggregates.

Finally, from a constructive point of view the use of HSC in the column vicinity in the compressive zone, that corresponds to the slab bottom, is much simpler than using it in the tension zone, that corresponds to the slab top.

\section{EXPERIMENTAL RESEARCH}

As mentioned above this experimental activity represents a continuation of a previous one performed by Inácio et al. [17]. This second phase of the experimental program consists in 5 specimens, 4 partially made using HSC and one in NSC. The geometry of the specimens is the same of the previous experimental campaign. The specimens measured $1650 \mathrm{~mm} \times 1650 \mathrm{~mm}$ with a thickness of $125 \mathrm{~mm}$ (h). The test setup is shown in Figure 1, the $1000 \mathrm{kN}$ hydraulic jack is positioned under the slab. 

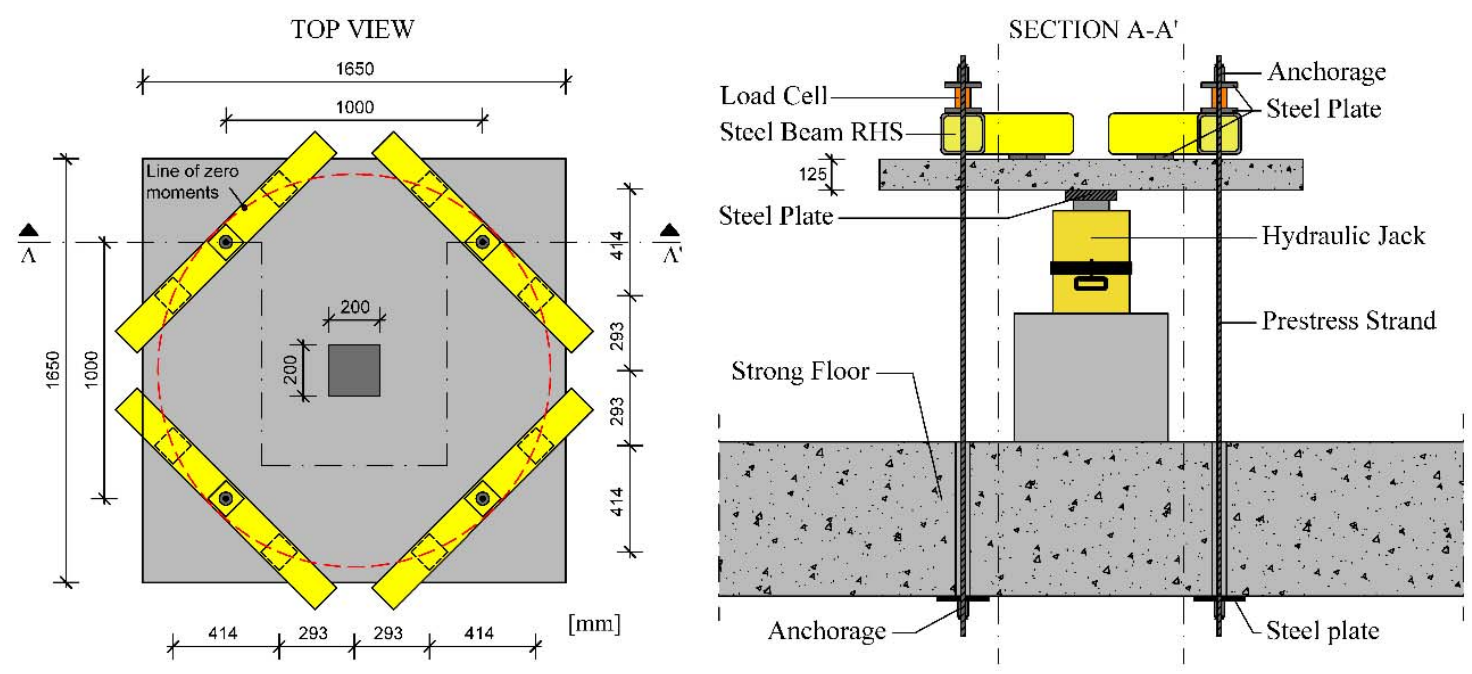

Figure 1 - Test setup

The load is spread by means a square steel plate $200 \mathrm{~mm}$ side and $50 \mathrm{~mm}$ thick. Eight reaction points are positioned on the top of the slab using four prestressed steel strands and spreader steel beams. The radius intercepting the loading points is equal to $r_{q}=765 \mathrm{~mm}$.

In the previous experimental activity the top longitudinal reinforcement ratio varied between $0.94 \%, 1.24 \%$ and $1.48 \%$. For the slab specimens presented along this paper, the top longitudinal reinforcement consisted of $12 \mathrm{~mm}$ bars, spaced every $90 \mathrm{~mm}$ in both orthogonal directions, with identical layout to the one used in specimen SHSC2, in order that their results can be compared directly. The bottom reinforcement consisted of $8 \mathrm{~mm}$ bars spaced $200 \mathrm{~mm}$ for all slabs. Both lower and upper reinforcement layers end in slab bound. The longitudinal reinforcement concrete clear cover of both faces was $20 \mathrm{~mm}$. During the manufacture of the specimens their mean effective depths (d) were measured and are presented in Table 1.

Table 1 - Main characteristics of the specimens

\begin{tabular}{|c|c|c|c|}
\hline Specimen & $\mathrm{d}(\mathrm{mm})$ & $\rho(\%)$ & HSC zone $(\mathrm{mm})$ \\
\hline SHSC2 $^{*}$ & 101.6 & 1.24 & Full \\
\hline SNSC4 $^{*}$ & 100.7 & 1.25 & none \\
\hline SHSC5 & 100.6 & 1.25 & $950 \times 950 \times 42$ \\
\hline SNSC6 & 100.2 & 1.25 & none \\
\hline SHSC7 & 100.0 & 1.26 & $575 \times 575 \times 42$ \\
\hline SHSC8 & 100.8 & 1.25 & $575 \times 575 \times 42$ \\
\hline SHSC9 & 100.9 & 1.25 & $950 \times 950 \times 42$ \\
\hline
\end{tabular}

*Specimens investigated by Inácio et al. [17].

The specimens SHSC2 and SNSC4 investigated in the previous experimental campaign have the same longitudinal reinforcement ratio adopted in this work, therefore in the following the results of these specimens are also shown to be compared with those of the present experimental campaign. The geometry of the specimens with rational use of HSC is shown in Figure 2. The thickness of the HSC layer is set equal to $42 \mathrm{~mm}$ that corresponds to about one third of the slab thickness. Two sizes of HSC layer are investigated, $575 \times 575 \mathrm{~mm}^{2}$ and $950 \times 950$ $\mathrm{mm}^{2}$. In the first case the HSC layer is extended $1.5 \cdot \mathrm{h}$ outside the support, while in the second case the HSC layer is extended 3.0.h outside the support. 
To ensure the desired geometry of the HSC region in accordance with Figure 2, a galvanized hexagonal steel net was used to act as a formwork for the HSC, as shown in Figure 3 . The region with HSC was cast first, soon after, the NSC part was cast. The adopted construction method allowed to obtain a monolithic connection between the two different concretes. Furthermore, just minimal deviations from the intended geometry were observed.
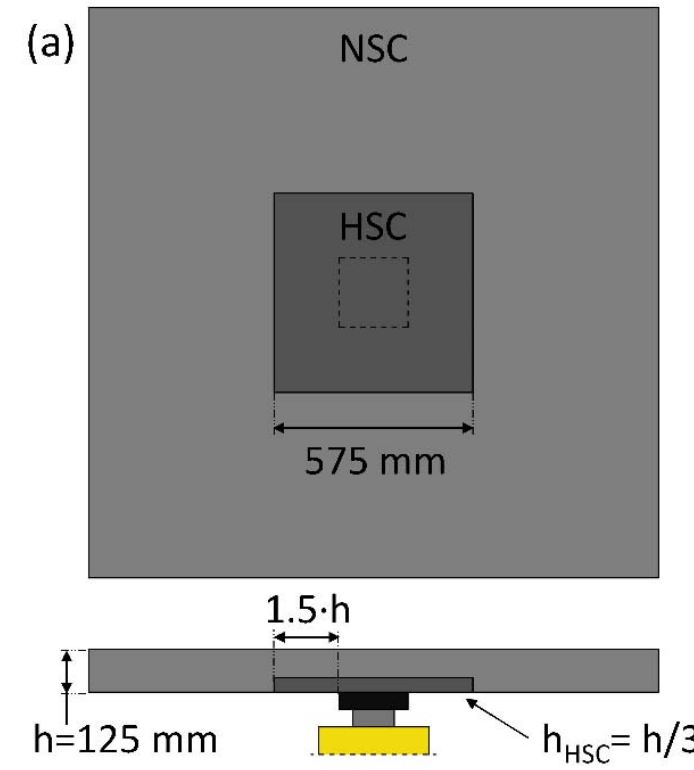

Figure 2 - Geometry of specimens with rational use of HSC: (a) 575x575x42 mm (b) 950x950x42 mm.
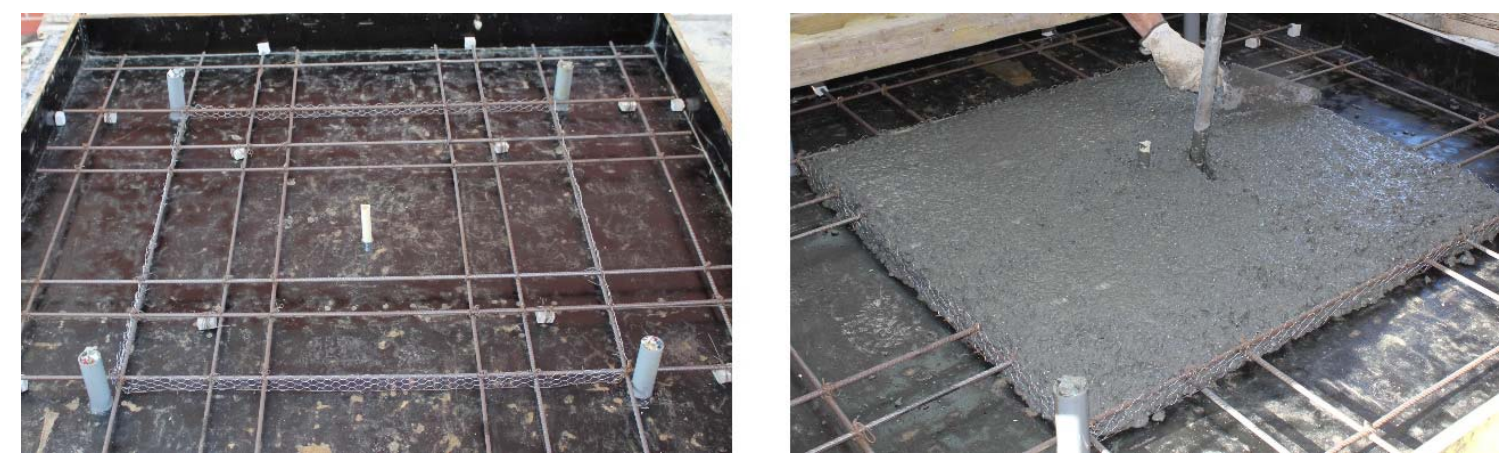

Figure 3 - Steel net used as a formwork for the HSC region (left), casting phase of the HSC region (right).

\subsection{Materials}

For the NSC crushed coarse limestone aggregate with fine sand were used, while for HSC crushed coarse basalt aggregates with medium and fine sand were adopted. The HSC was produced using Portland cement type CEM I 52.5R while the NSC was produced with Portland cement CEM II/B-L $32.5 \mathrm{~N}$. Silica fume, in amount equal to $10 \%$ of the cement weight, was added during the mixing process to enhance the mechanical proprieties of the HSC, as suggested by several authors [23-26]. Three different NSC mixtures were used to evaluate the influence of the NSC mechanical characteristics on the slabs behaviour. For NSC the water cement ratio was set equal to $58 \%$ while in the HSC was kept equal to $28 \%$. Therefore, in the HSC superplasticizer was also added during the mixing to improve the workability. The 
maximum aggregate size resulted $13.9 \mathrm{~mm}$ for the HSC and 13.2 for the NSC. The materials quantities used in the concrete mixtures are listed in Table 2.

Table 2 - Concrete mix proportions $\left(\mathrm{kg} / \mathrm{m}^{3}\right)$

\begin{tabular}{|c|c|c|c|c|c|}
\hline \multirow[b]{2}{*}{ Mix design } & \multirow{2}{*}{$\begin{array}{c}\text { HSC } \\
\text { All spec. }\end{array}$} & \multicolumn{4}{|c|}{ NSC } \\
\hline & & $\begin{array}{l}\text { SHSC2* and } \\
\text { SNSC4* }\end{array}$ & SHSC5 & $\begin{array}{l}\text { SNSC6 and } \\
\text { SHSC7 }\end{array}$ & $\begin{array}{l}\text { SHSC8 and } \\
\text { SHSC9 }\end{array}$ \\
\hline Cement & $\begin{array}{c}500 \\
\text { (CEM I } \\
52.5 \mathrm{R})\end{array}$ & $\begin{array}{c}320 \\
\text { (CEM II/B-L } \\
32.5 \mathrm{~N})\end{array}$ & $\begin{array}{c}450 \\
\text { (CEM II/B-L } \\
32.5 \mathrm{~N})\end{array}$ & $\begin{array}{c}280 \\
\text { (CEM II/B-L } \\
32.5 \mathrm{~N} \text { ) }\end{array}$ & $\begin{array}{c}320 \\
\text { (CEM II/B-L } \\
32.5 \mathrm{~N} \text { ) }\end{array}$ \\
\hline Silica fume & 50 & - & - & - & - \\
\hline $\begin{array}{c}\text { Coarse aggregate } \\
(8 / 16)\end{array}$ & 1088 & 906 & 871 & 880 & 906 \\
\hline Medium sand (2/4) & 489 & 626 & 655 & 597 & 626 \\
\hline Fine sand $(0 / 2)$ & 249 & 286 & 117 & 311 & 286 \\
\hline Superplasticizer & 8.43 & - & - & - & - \\
\hline Water** & $\begin{array}{l}139.1 \\
(28 \%)\end{array}$ & $\begin{array}{l}184.3 \\
(58 \%)\end{array}$ & $\begin{array}{l}208.2 \\
(58 \%)\end{array}$ & $\begin{array}{l}163.4 \\
(58 \%)\end{array}$ & $\begin{array}{l}184.3 \\
(58 \%)\end{array}$ \\
\hline
\end{tabular}

*Specimens investigated by Inácio et al. [17], **the water cement ratio is also provided in \%.

The concrete compressive $\left(f_{c}\right)$ and tensile $\left(f_{c t}\right)$ strengths were determined on $150 \times 300 \mathrm{~mm}$ cylinders, according to EN 12390-3 [27] and EN 12390-6 [28] respectively. The concrete modulus of elasticity $\left(E_{c}\right)$ was determined on $150 \times 300 \mathrm{~mm}$ cylinders subjected to compression load according to EN 12390-13 [29]. The modulus of elasticity was calculated during loading and unloading cycles between two threshold values, the maximum stress was set equal to $1 / 3 \cdot f_{c}$ while the minimum stress was $0.50 \mathrm{MPa}$. Characteristics of concrete at the date of slab testing are shown in Table 3.

Table 3 - Mechanical properties of concrete

\begin{tabular}{|c|c|c|c|c|c|c|c|}
\hline \multirow{2}{*}{ Specimen } & \multirow{2}{*}{$\begin{array}{c}\text { Age of concrete } \\
\text { (days) }\end{array}$} & \multicolumn{3}{|c|}{ NSC } & \multicolumn{3}{c|}{$H S C$} \\
\cline { 3 - 8 } & $\mathrm{f}_{\mathrm{c}}(\mathrm{MPa})$ & $\mathrm{f}_{\mathrm{ct}, \text { sp }}(\mathrm{MPa})$ & $\mathrm{E}_{\mathrm{c}}(\mathrm{MPa})$ & $\mathrm{f}_{\mathrm{c}}(\mathrm{MPa})$ & $\mathrm{f}_{\mathrm{ct}, \text { sp }}(\mathrm{MPa})$ & $\mathrm{E}_{\mathrm{c}}(\mathrm{MPa})$ \\
\hline SHSC2 & 62 & - & - & - & 130.1 & 8.4 & 55500 \\
\hline SNSC4* & 59 & 35.9 & 2.6 & 32600 & - & - & - \\
\hline SHSC5 & 62 & 58.0 & 4.0 & 40200 & 118.5 & 8.0 & 53100 \\
\hline SNSC6 & 60 & 23.0 & 2.5 & 31500 & - & - & - \\
\hline SHSC7 & 60 & 24.7 & 2.6 & 34000 & 127.3 & 7.2 & 53000 \\
\hline SHSC8 & 59 & 38.9 & 3.1 & 35700 & 125.2 & 7.5 & 53800 \\
\hline SHSC9 & 59 & 39.1 & 2.8 & 37200 & 125.8 & 7.9 & 52500 \\
\hline
\end{tabular}

*Specimens investigated by Inácio et al. [17].

The yield stress $\left(f_{y}\right)$ and the tensile strength $\left(f_{t}\right)$ of the longitudinal reinforcement was determined according to [30] performing direct tensile tests on rebar samples. Characteristics of steel reinforcement are shown in Table 4.

Table 4 - Mechanical properties of steel reinforcement

\begin{tabular}{|c|c|c|}
\hline \multirow{2}{*}{ Specimen } & \multicolumn{2}{|c|}{ Reinforcement } \\
\cline { 2 - 3 } & $\mathrm{f}_{\mathrm{y}}(\mathrm{MPa})$ & $\mathrm{f}_{\mathrm{t}}(\mathrm{MPa})$ \\
\hline SHSC2 $^{*}$ & 523.4 & 671.4 \\
\hline SNSC4 & 532.3 & 642.6 \\
\hline SHSC5 & 523.4 & 671.4 \\
\hline SNSC6 & 523.4 & 671.4 \\
\hline SHSC7 & 523.4 & 671.4 \\
\hline SHSC8 & 532.3 & 642.6 \\
\hline SHSC9 & 532.3 & 642.6 \\
\hline
\end{tabular}

*Specimens investigated by Inácio et al. [17]. 


\subsection{Instrumentation}

During the tests both loads and vertical displacements were measured. The loads were monitored by means of four load cells placed in correspondence of the steel strands. Vertical displacements were measured using 11 linear variable differential transformers (LVDT). The arrangement of the LVDTs is shown in Figure 4, LVDTs D2 to D7 were placed in the direction of the higher effective depth, while LVDTs D8 to D11 were placed in the direction of the lower effective depth.
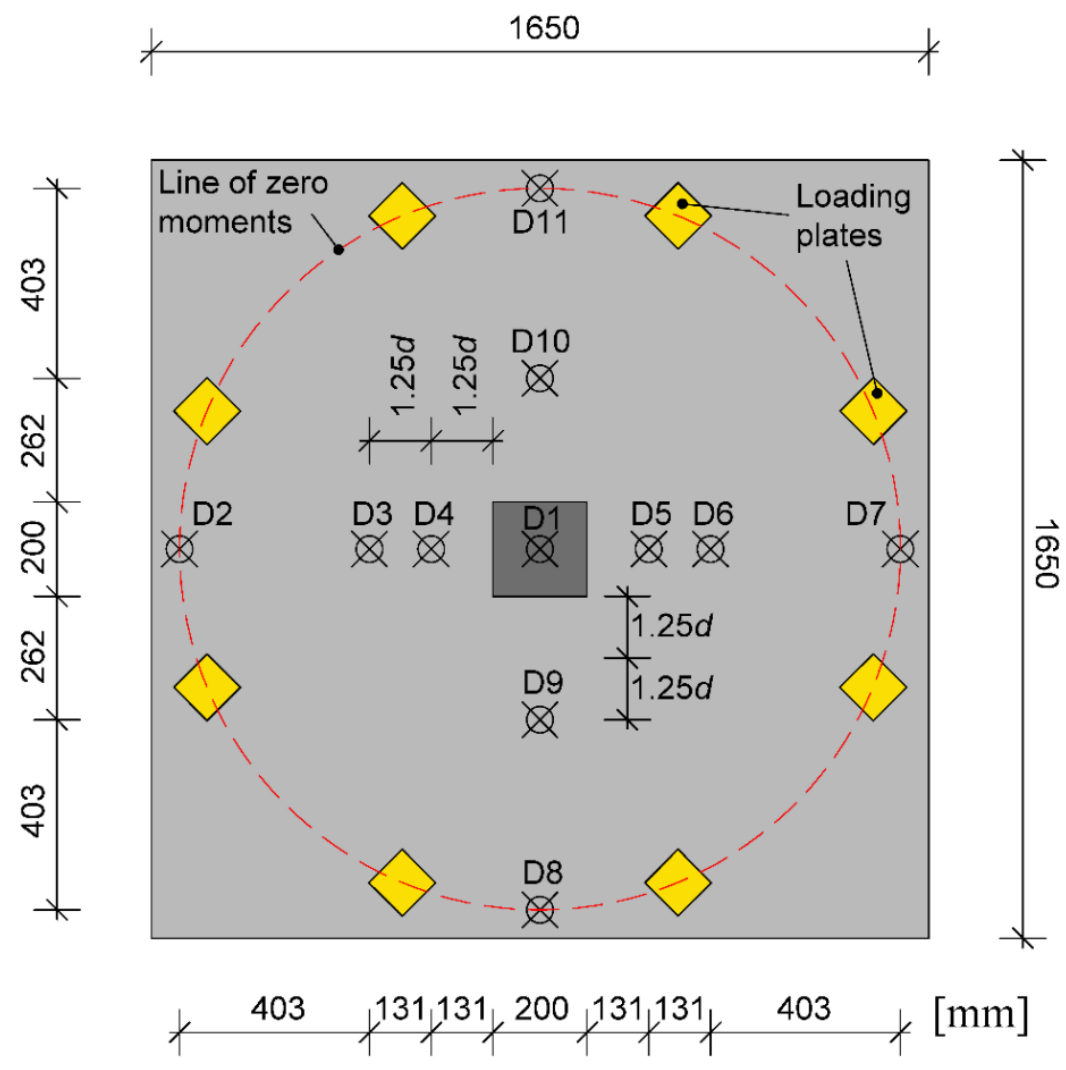

Figure 4-LVDT's and loading plate's position

Strains of top longitudinal reinforcement were also measured by couples of strain gauges glued to the rebars. The strain gauges were placed on the top reinforcement bars with higher effective depth. The position of the strain gauges is shown in Figure 5. 


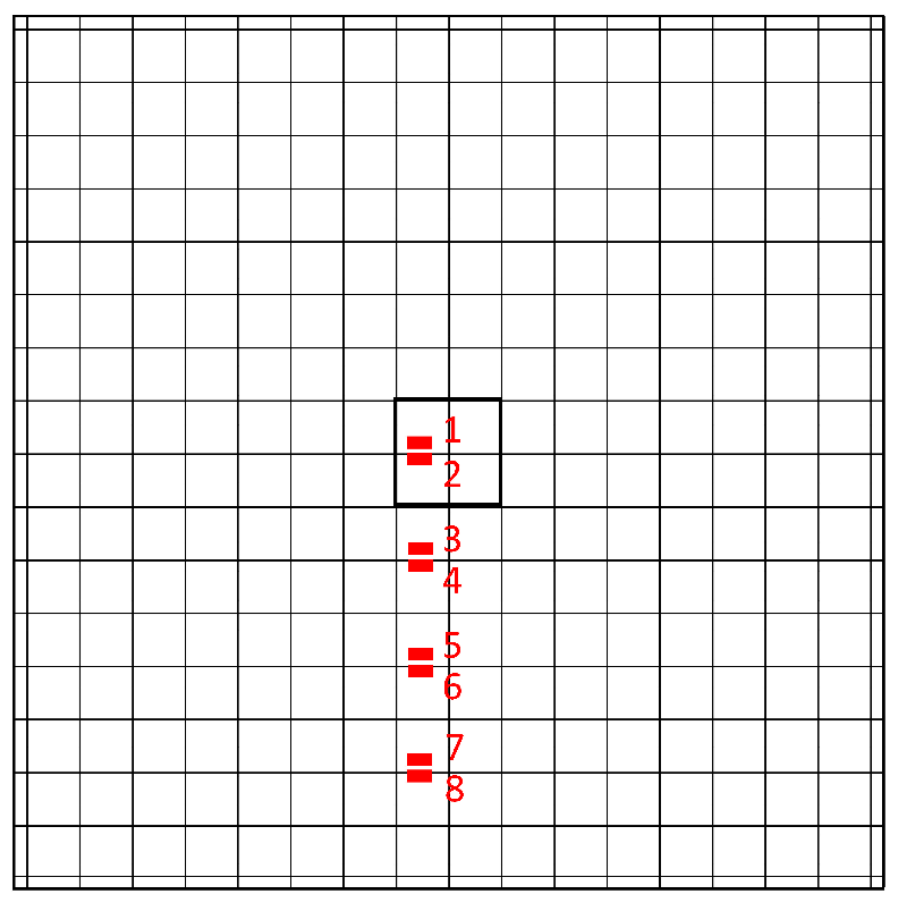

Figure 5 - Strain gauges position

\section{EXPERIMENTAL RESULTS}

\subsection{Vertical displacements}

The load-deflection relationships were obtained calculating the relative displacement between the center of the slab and the generic LVDT. For each couple of opposite LVDTs the average value of relative displacement is provided. The initial load results different from zero since it accounts the self-weight of the specimen and the equipment placed on the slab. The loaddisplacement curves of all specimens, included SHSC2 and SNSC4 investigated by Inácio et al. [17], are provided in Figure 6.
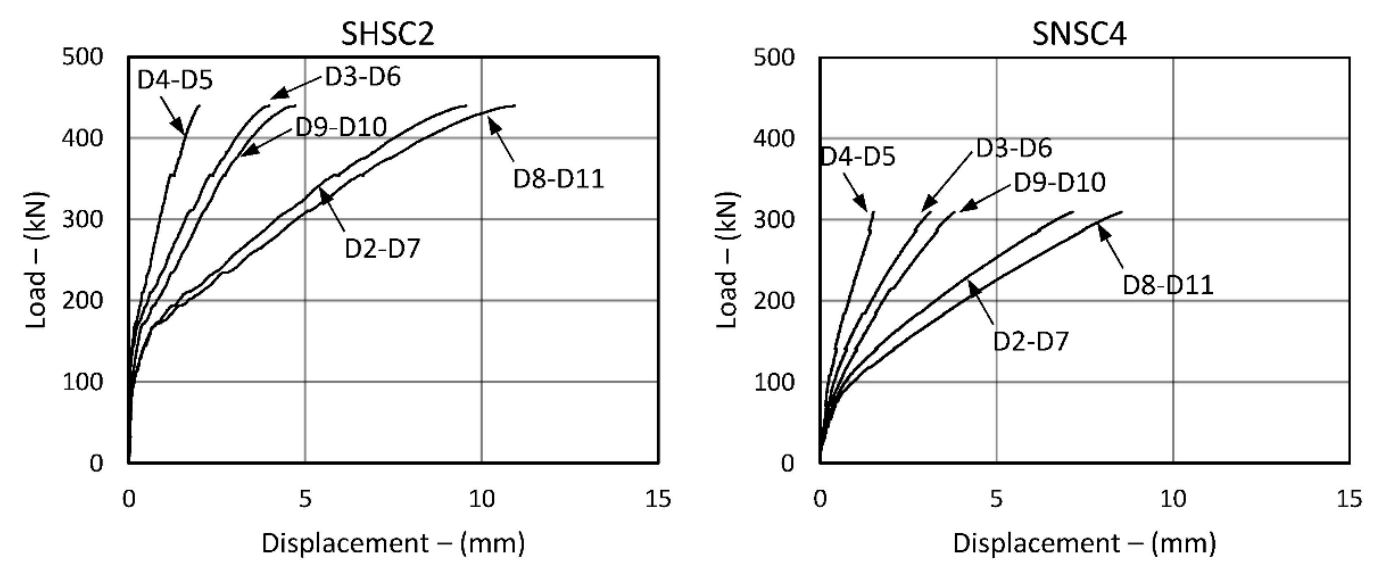

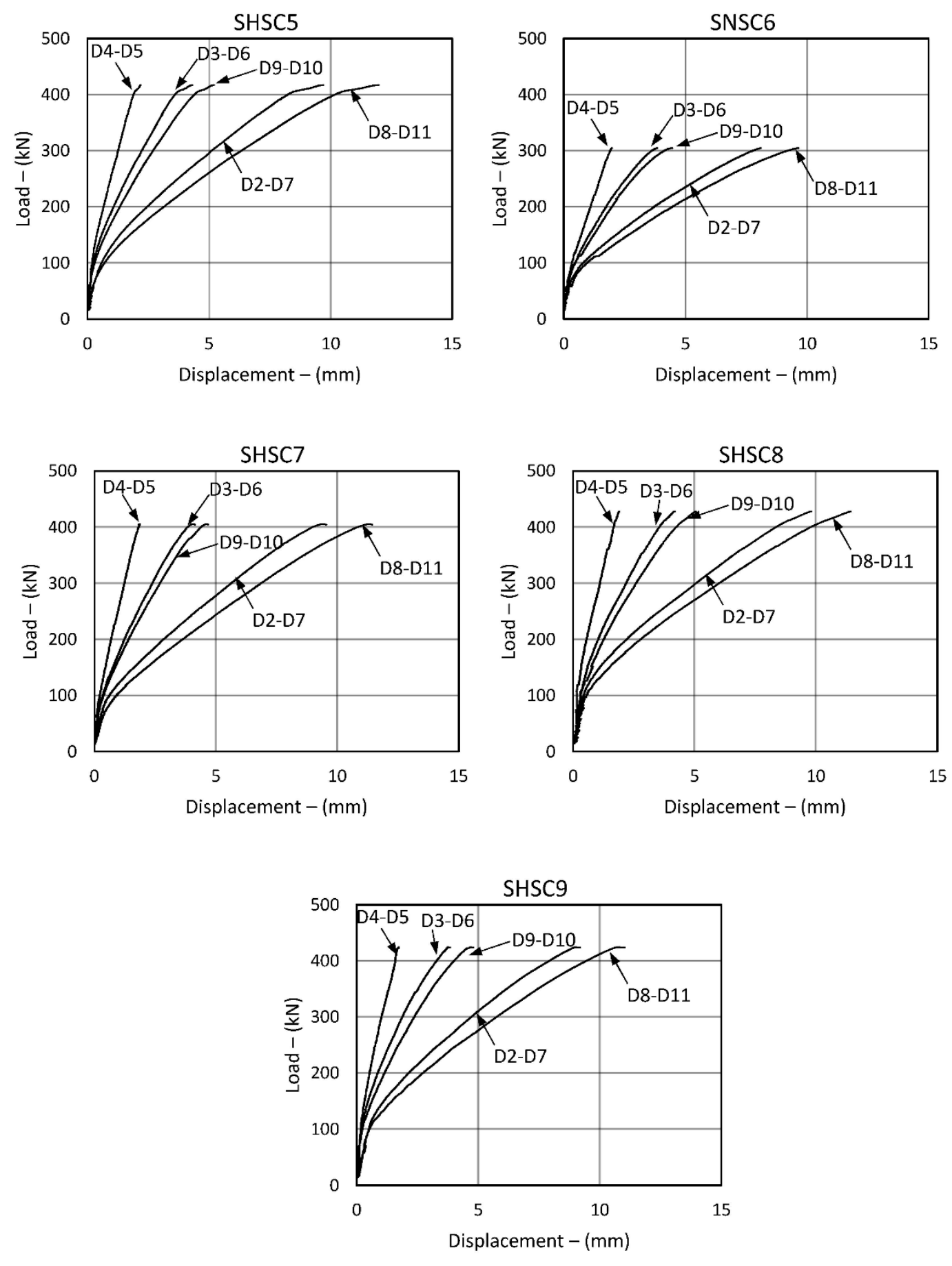

Figure 6 - Load-displacement curves

In the specimen SHSC2, completely made in HSC, the flexural cracking occurs at about $150 \mathrm{kN}$ while for the others the cracking occurs between $50 \mathrm{kN}$ and $100 \mathrm{kN}$. This different behavior exhibited by the specimen SHSC2 is due to the higher tensile strength provided by the HSC. The specimens partially made in HSC do not show this behavior since the HSC is placed only in compression zone. Therefore, the cracking moment of these slabs is comparable to that provided by the specimens casted only with NSC (SNSC4 and SNSC6). As expected, the loaddeflection curves were stiffer before flexural cracks start to form and develop. The vertical displacements at failure for all the slabs with HSC were similar, showing that the use of a 
limited quantity of HSC did not affected significantly the slab's deformation capacity. The slabs casted enterally with NSC (SNSC4 and SNSC6) presented lower vertical deformations at failure, but also lower failure loads.

\subsection{Longitudinal reinforcement strains}

The strain evolution of the top reinforcement is obtained from the average measure of each couple of strain gauges glued at the bars. The load-strain curves of all specimens are provided in Figure 7. A dashed line marks the considered yield strain for each specimen. The strain evolution in the top reinforcement highlights the beneficial effect of the HSC. The specimen SHSC2, completely made in HSC, showed three strain measures exceeding the strain at yielding of reinforcement, corresponding about to $2.6 \%$. Conversely the two specimens made in NSC, SNSC4 and SNSC6, showed strain values lower than $2.0 \%$. Finally, the specimens with partial use of HSC showed two strain measures exceeding the yielding strain. Actually, for the specimen SHSC8 there is only one measure greater than $2.6 \%$, because the strain gauges number 1-2 placed on the center of the slab misfunctioned without recording any data. However, the result of the strain gauge number 3 suggests that probably also the couple 1-2 exceeded the yielding strain. The development of a full flexural yield line was not achieved in any specimens.

It can be observed that in some bars the strains show a sudden increase for a load level corresponding roughly to the beginning of the flexural cracking development. This is especially true for the slab SHSC2 made entirely of HSC. This behavior may be justified by the transfer of stresses between the tensioned concrete and the reinforcement bars that occur at moment of crack formation, which is higher for that slab since the concrete in tension is also HSC.
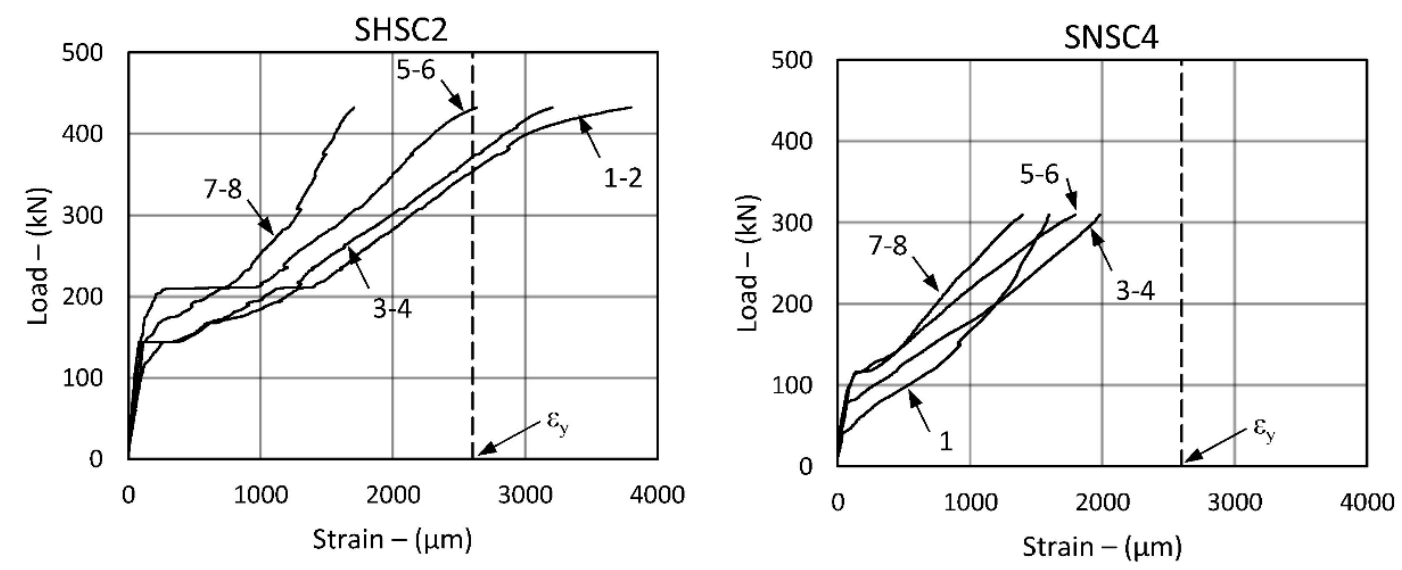

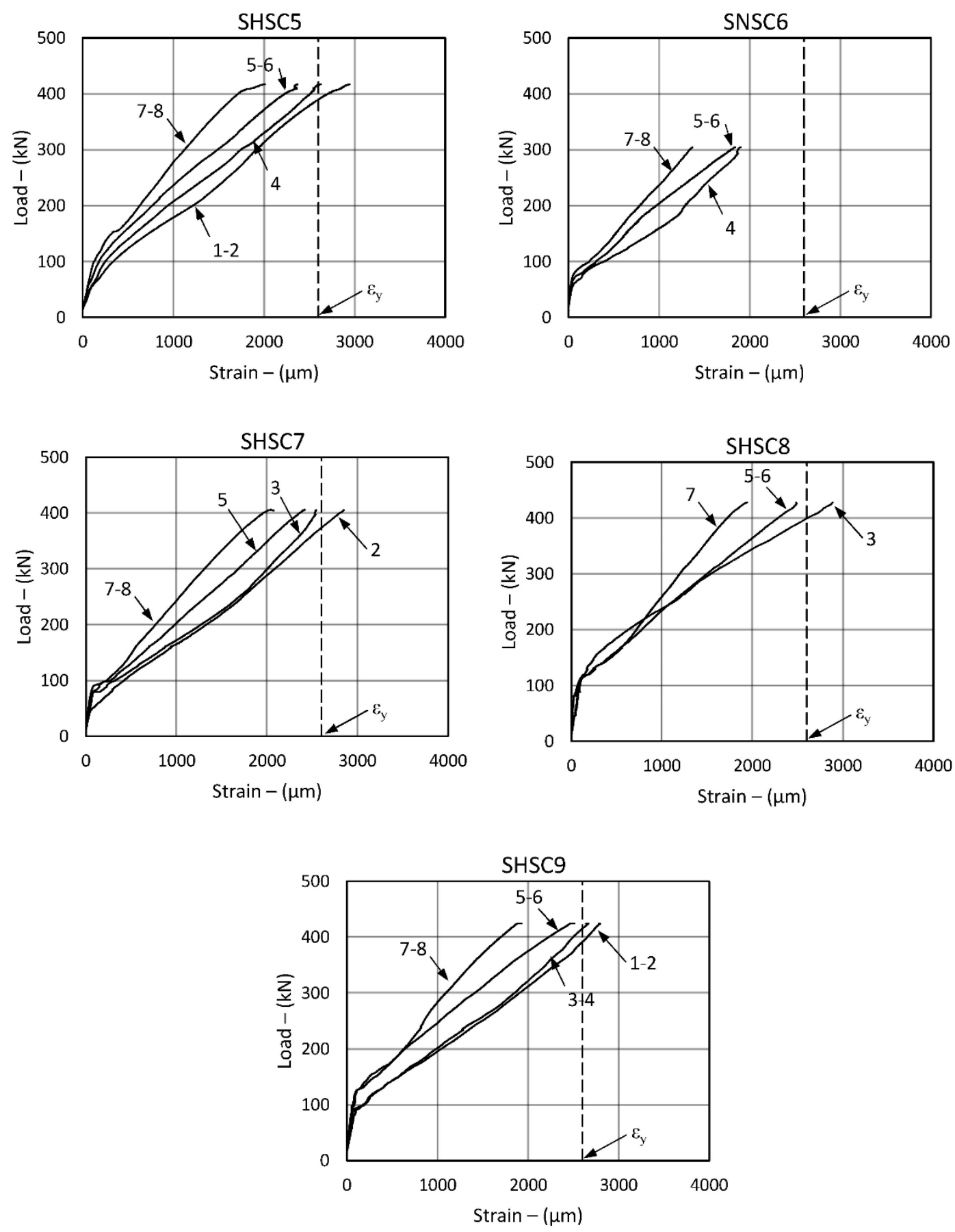

Figure 7 - Strain-Load curves

\subsection{Slabs load capacity and failure mode}

All specimens failed by punching. The saw cuts of the tested specimens are shown in Figure 8. The presence of HSC, in hybrid slabs, is made evident by the darker color compared to NSC. 


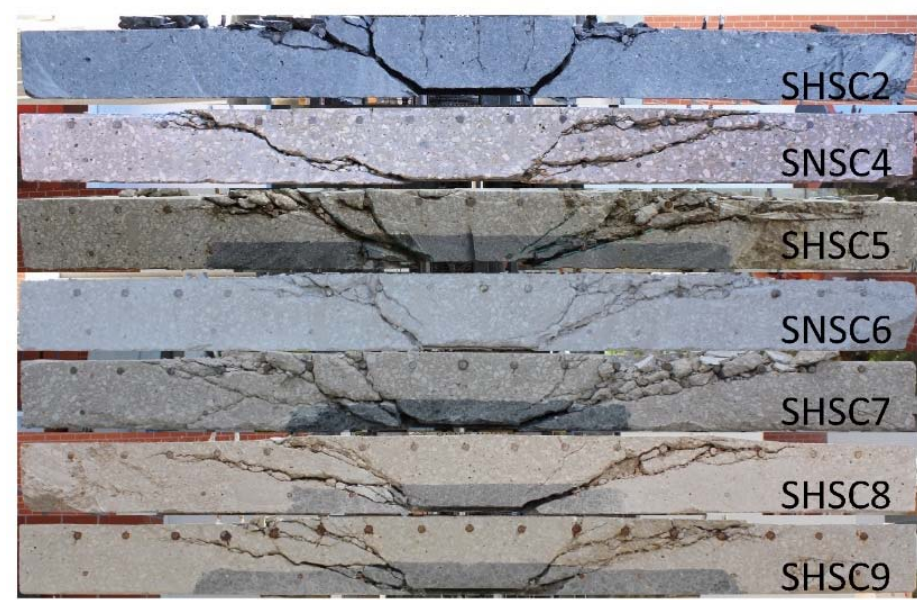

Figure 8 - Saw cuts of tested specimens

According to Bompa and Onet [31] the main variable that affects the crack inclination is the slab slenderness. In this case, the slab geometry is kept unchanged for the entire research program, therefore almost the same crack inclination for all the specimens was expected. At first sight, the critical cracks provided by the specimens SHSC2 and SNSC6 appear more inclined than those provided by the other specimens. Actually, almost all the other specimens showed two main cracks, one more inclined $\left(\approx 40^{\circ}\right)$, as specimens SHSC2 and SNSC6, and one less inclined $\left(\approx 15^{\circ}\right)$.

In Figure 9 the comparison between the load-displacement curves of all specimens is provided. The displacements are referred to the LVDTs D8-D11, which identify the direction of lower effective depth.

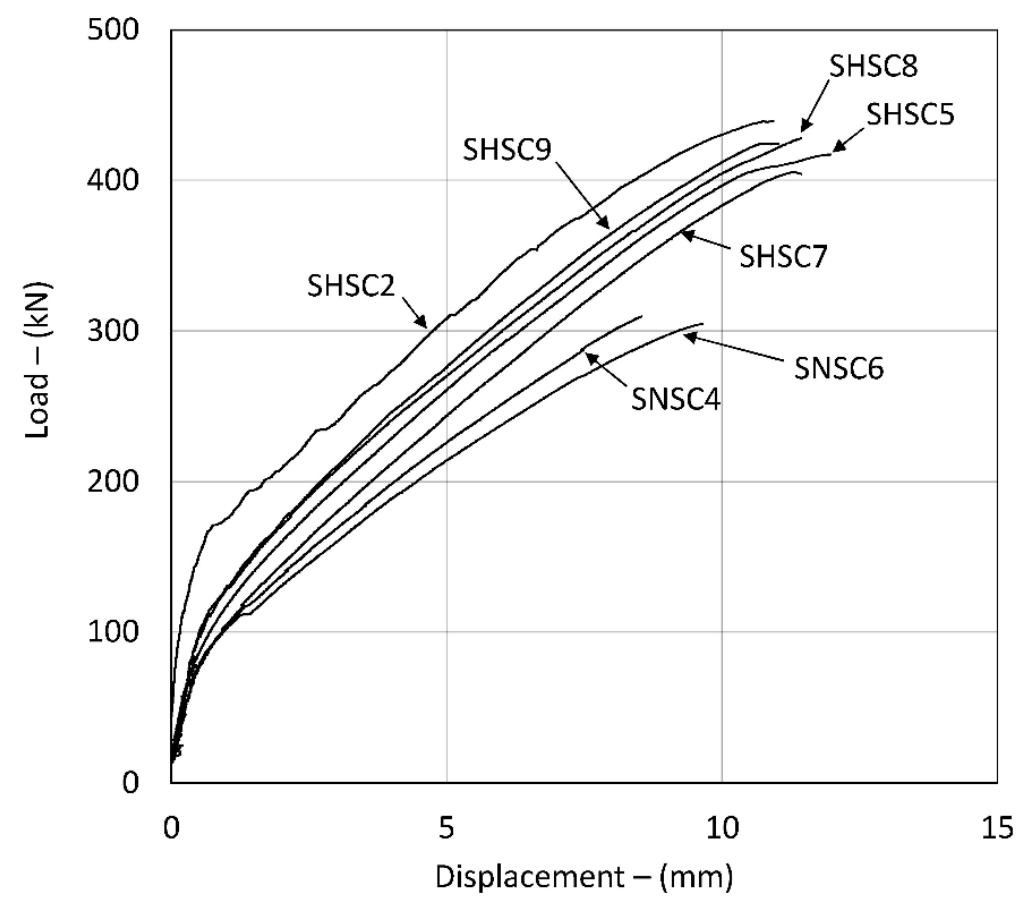

Figure 9 - Comparison between load-displacement curves, LVDTs D8-D11. 
From the comparison between the load-displacement curves it is possible to distinguish three groups: the slab made in entirely of HSC (SHSC2), the hybrid slabs (SHSC5, SHSC7, SHCS8 and SHSC9) and the slabs made in of NSC (SNSC4 and SNSC6). The load-displacement curve provided by the specimen SHSC2 appears shifted upward with respect to the other curves. Furthermore, both cracking and failure loads resulted the highest. The load-displacement curves exhibited by the NSC specimens resulted slightly less stiff than the others while the punching loads resulted much lower than those provided by the other slabs. Finally, the hybrid slabs provided an intermediate behavior between the latter. Cracking loads resulted almost equal to those provided by the NSC slabs, while failure loads and deformation capacity resulted close to that provided by the SHSC2 specimen, made completely of HSC. The experimental failure loads are listed in Table 5.

Table 5 - Main characteristics of the specimens and failure loads

\begin{tabular}{|c|c|c|c|c|c|c|c|c|c|c|}
\hline \multirow[b]{2}{*}{ Specimen } & \multirow[b]{2}{*}{ HSC zone (mm) } & \multirow[b]{2}{*}{$\mathrm{d}(\mathrm{mm})$} & \multirow[b]{2}{*}{$\rho(\%)$} & \multicolumn{2}{|c|}{$\mathrm{f}_{\mathrm{c}}(\mathrm{MPa})$} & \multicolumn{2}{|c|}{$\mathrm{d}_{\mathrm{g}}(\mathrm{mm})$} & \multirow[b]{2}{*}{$\mathrm{f}_{\mathrm{y}}(\mathrm{MPa})$} & \multicolumn{2}{|c|}{ Failure loads } \\
\hline & & & & NSC & HSC & NSC & HSC & & $\begin{array}{l}V_{\text {exp }} \\
\text { (kN) }\end{array}$ & $\begin{array}{c}\Delta V^{* *} \\
(\%)\end{array}$ \\
\hline SHSC2* & Full & 101.6 & 1.24 & - & 130.1 & - & 13.9 & 523.4 & 439 & $+43 \%$ \\
\hline SNSC4* & none & 100.7 & 1.25 & 35.9 & - & 13.2 & - & 532.3 & 310 & - \\
\hline SHSC5 & $950 \times 950 \times 42$ & 100.6 & 1.25 & 58.0 & 118.5 & 13.2 & 13.9 & 523.4 & 417 & $+35 \%$ \\
\hline SNSC6 & none & 100.2 & 1.25 & 23.0 & - & 13.2 & - & 523.4 & 305 & - \\
\hline SHSC7 & $575 \times 575 \times 42$ & 100.0 & 1.26 & 24.7 & 127.3 & 13.2 & 13.9 & 523.4 & 405 & $+31 \%$ \\
\hline SHSC8 & $575 \times 575 \times 42$ & 100.8 & 1.25 & 38.9 & 125.2 & 13.2 & 13.9 & 532.3 & 428 & $+39 \%$ \\
\hline SHSC9 & $950 \times 950 \times 42$ & 100.9 & 1.25 & 39.1 & 125.8 & 13.2 & 13.9 & 532.3 & 424 & $+38 \%$ \\
\hline
\end{tabular}

*Specimens investigated by Inácio et al. [17], **The reference failure load is provided by the average of SNSC4 and SNC6 failure loads.

As shown in Table 5 the rational use of HSC provided very good results in terms of punching strength. The average punching load provided by the hybrid slabs resulted equal to $419 \mathrm{kN}$ that is about $5 \%$ less than the failure load provided by the slab completely made in HSC. When compared with the average failure loads of the slabs made with NSC, the hybrid slabs showed an average increase of about $36 \%$ of the load capacity. In the following, this important experimental evidence is explained by means of an analytical approach.

\section{ANALYTICAL APPROACH}

As shown above, the partial use of HSC allowed for the increase the punching strength up to $39 \%$. The introduction of the HSC near the column in the compression zone provides two beneficial effects. The first is related to the enhancement of the flexural strength while the second consists in the increase of the interlocking strength. Both these effects contribute to enhance the punching strength of the slab. The Critical Shear Crack Theory (CSCT), developed by Muttoni in 2008 [32] is a comprehensive model for the determination of the punching strength of reinforced concrete flat slabs. This model accounts both the flexural behaviour of the slab and the interlocking strength of the critical surface. For this reason, this model is particularly suitable for the interpretation of the experimental results of this type of slabs. The application of the CSCT to slabs with partial use of HSC is presented in the following.

In general, for layered slabs the CSCT should be modified in two respects [33]. The first is related to the determination of the load-rotation curve and the second regards the calculation of the failure criterion. 
The load-rotation curve is determined by imposing the equilibrium conditions to the slab sector (Figure 10). The equilibrium of the slab sector can be expressed as follows [32]:

$V \cdot \frac{\Delta \varphi}{2 \pi} \cdot\left(r_{q}-r_{c}\right)=-m_{r} \cdot \Delta \varphi \cdot r_{0}-\Delta \varphi \cdot \int_{r_{0}}^{r_{s}} m_{t} \cdot d r$

The presence of HSC in the compressive zone near the column alters the radial moment $\left(m_{r}\right)$ and the integral of the tangential moments $\left(m_{t}\right)$. Thanks to the presence of the HSC the flexural capacity of the slab is enhanced and the load-rotation curve is arisen.
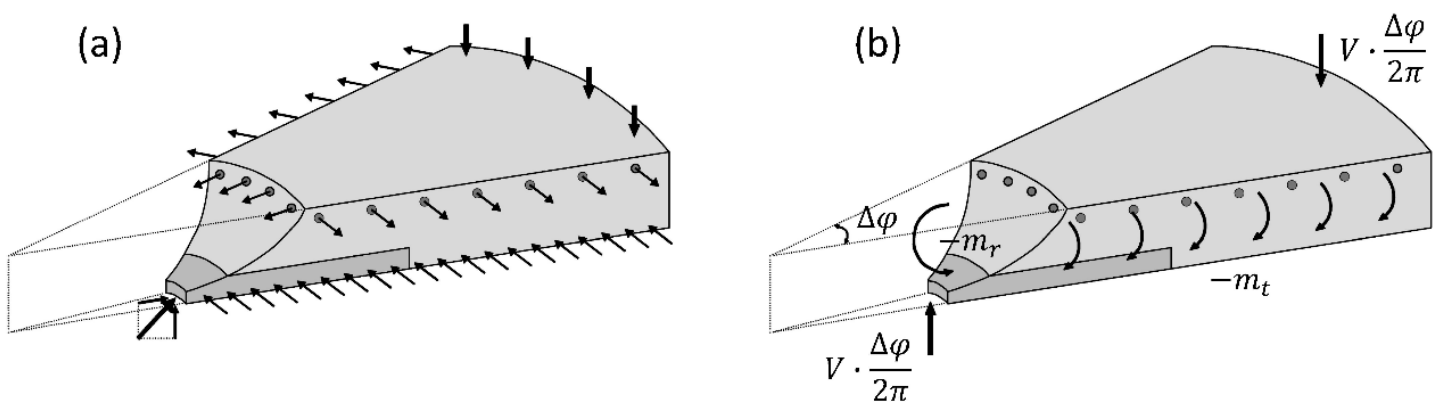

Figure 10 - Slab sector with hybrid use of concrete: (a) forces in concrete and reinforcement (b) resultant internal and external forces acting on the slab sector

However, the most important modification provided by the partial use of HSC consists in the increase of the interlocking strength. According to Vecchio and Collins [34] the interlocking force that can be transmitted across a crack is a function of the concrete compressive strength $\left(f_{c m}\right)$, the maximum diameter $\left(d_{g}\right)$ of the aggregate and the crack width $(w)$. The failure criterion proposed by Muttoni in 2008 [32] (equation (2)) for R/C flat slabs without shear reinforcement, reflects this model.

$V_{R}(\psi)=\frac{3}{4} \cdot \frac{b_{0} \cdot d \cdot \sqrt{f_{c}}}{1+15 \cdot \frac{\psi \cdot d}{d_{g 0}+d_{g}}}$

In general, the interlocking strength increases at concrete compressive strength increasing. However in elements made of high-strength concrete, cracks tend to develop through the aggregate rather than passing around them [35]; therefore for high strength concrete $d_{g}$ should be corrected accounting for the reduced roughness of the failure surface [36]:

$d_{g, H S C}=d_{g} \cdot \min \left(\left(\frac{60}{f_{c m}}\right)^{2} ; 1\right)$

In Figure 11 the relationship between rotation $(\psi)$ and punching strength $\left(V_{R} / b_{\circ} \cdot d\right)$, calculated according to equations (2) and (3), is shown at varying of the concrete compressive strength $\mathrm{f}_{\mathrm{cm}}$. The effective depth $\mathrm{d}$ is assumed equal to $100 \mathrm{~mm}$, the maximum aggregate size is chosen equal to $13.9 \mathrm{~mm}$ and the concrete compressive strength is varied from $20 \mathrm{MPa}$ to $140 \mathrm{MPa}$ (20 MPa, $40 \mathrm{MPa}$, $60 \mathrm{MPa}, 80 \mathrm{MPa}, 100 \mathrm{MPa}, 120 \mathrm{MPa}$ and $140 \mathrm{MPa}$ ). 


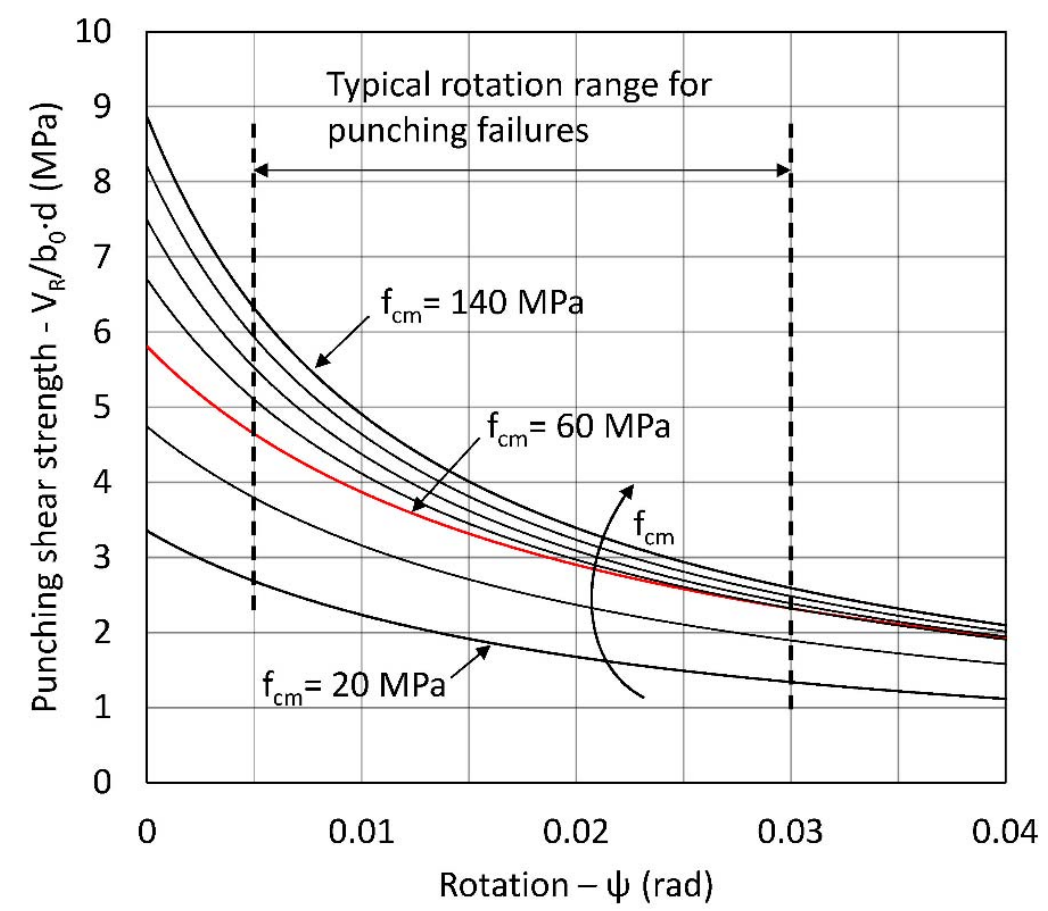

Figure 11 - Relationship between rotation $(\psi)$ and punching shear strength $V_{R} / b_{0} \cdot d$ according to Muttoni et al. [32] at varying the concrete compressive strength $\left(f_{\mathrm{cm}}\right)$.

As shown in Figure 11, considering the typical rotation range for punching failure, at concrete compressive strength increasing the punching strength increases. However, the beneficial effect achieved by increasing the concrete compressive strength for $f_{c m}>60 \mathrm{MPa}$ tends to be lower than that achieved for $\mathrm{f}_{\mathrm{c}}<60 \mathrm{MPa}$, due to the reduced roughness of the failure surface for high strength concrete.

For hybrid slabs, to account for the presence of different concrete strengths and maximum aggregate sizes, Inácio [9] proposed the introduction of an equivalent concrete. The equivalence should be intended in terms of interlocking strength.

The following equivalent quantities are proposed:

$\begin{cases}f_{c, e q}=\frac{f_{c, H S C} \cdot h_{H S C}+f_{c, N S C} \cdot\left(x-h_{H S C}\right)}{x} & x>h_{H S C} \\ f_{c, e q}=f_{c, H S C} & x \leq h_{H S C}\end{cases}$

$d_{g, e q}=d_{g, H S C}$

where $h_{H S C}$ is the depth of HSC layer and $x$ is the depth of the compressive zone. Therefore, the punching strength is calculated considering the equivalent concrete compressive strength (4) and the maximum aggregate size of the high strength concrete (5). Usually, for slender slabs the depth of the compressive zone $x$ could be calculated according to the flexural theory, conversely for compact slabs or for footings the flexural theory leads to an underestimation of the compressive depth. Further information about the determination of the compressive depth are found here $[36,37]$. In the present case, the flexural theory has been used.

The choice of weighting the concrete strengths on the compressive depth $(x)$ only, has been suggested by the experimental results. In this experimental campaign the depth of the HSC 
$\left(\mathrm{h}_{\mathrm{HSC}}=42 \mathrm{~mm}\right)$ is always higher than the compressive depth $(\mathrm{x} \approx 22 \mathrm{~mm})$; this thin layer of HSC allowed for an enhancement of the punching strength comparable to that achieved by the slab made entirely of high-strength concrete (Table 5). However, if the depth of the HSC is lower than the depth of the compressive zone, it is reasonable to account the strength of the upper concrete layer also (4).

With regards to the choice of the equivalent maximum aggregate size the authors suggest considering the HSC only. Conversely, the use of a weighted average of the maximum aggregate size could lead to hybrid slabs more resistant than slabs made completely of HSC. Indeed, the maximum aggregate size of HSC should be reduced according equation to (3) while the maximum aggregate size of NSC could be assumed without any reduction.

The scenario of hybrid slabs with more strength than slabs completely made of HSC is considered unlikely for a wide range of NSC compressive strength and aggregate size. For effective depth higher than $200 \mathrm{~mm}$ and maximum aggregate size higher than $30 \mathrm{~mm}$ the scenario of hybrid slab more resistant than slabs completely made of HSC could occur if a NSC with a compressive strength close to $60 \mathrm{MPa}$ is used. However, also in this case the proposed approach results on the safe side since it leads to a lower punching strength.

However, for a full validation of the proposed equations further experimental activities are needed. In particular, different depths of the HSC layer and different values of maximum aggregate size should be investigated.

In this experimental campaign the depth of the HSC is always higher than the compressive depth, therefore the failure criterion becomes:

$V_{R}(\psi)=\frac{3}{4} \cdot \frac{b_{0} \cdot d \cdot \sqrt{f_{c, H S C}}}{1+15 \cdot \frac{\psi \cdot d}{d_{g 0}+d_{g, H S C}}}$

In Table 6 both experimental results $\left(\mathrm{V}_{\exp }, \psi_{\exp }\right)$ and analytical predictions $\left(\mathrm{V}_{\mathrm{th}}, \psi_{\mathrm{th}}\right)$ are presented.

Table 6 - Comparison with the CSCT

\begin{tabular}{|c|c|c|c|c|c|c|c|c|c|c|c|}
\hline \multirow[b]{2}{*}{ Specimen } & \multirow{2}{*}{$\begin{array}{l}\text { HSC zone } \\
(\mathrm{mm})\end{array}$} & \multicolumn{2}{|c|}{$\mathrm{f}_{\mathrm{c}}(\mathrm{MPa})$} & \multirow{2}{*}{$\begin{array}{l}d_{g, \text { eq }} \\
(\mathrm{mm})\end{array}$} & \multirow{2}{*}{$\begin{array}{c}f_{y} \\
(\mathrm{MPa})\end{array}$} & \multicolumn{2}{|c|}{ Loads } & \multicolumn{2}{|c|}{ Rotations } & \multicolumn{2}{|c|}{ Comparison } \\
\hline & & NSC & $\mathrm{HSC}$ & & & $\begin{array}{l}V_{\text {exp }} \\
\text { (kN) }\end{array}$ & $\begin{array}{l}V_{\text {th }} \\
(k N)\end{array}$ & $\begin{array}{l}\psi_{\exp } \\
(\%)\end{array}$ & $\begin{array}{l}\psi_{\text {th }} \\
(\%)\end{array}$ & $\begin{array}{c}V_{\text {exp }} / V_{\text {th }} \\
(-)\end{array}$ & $\begin{array}{c}\psi_{\exp } / \psi_{\text {th }} \\
(-)\end{array}$ \\
\hline SHSC2* & Full & - & 130.1 & 2.96 & 523.4 & 439 & 423 & $1.54 \%$ & $1.62 \%$ & 1.04 & 0.95 \\
\hline SNSC4* & none & 35.9 & - & 13.2 & 532.3 & 310 & 308 & $1.18 \%$ & $1.24 \%$ & 1.01 & 0.95 \\
\hline SHSC5 & $950 \times 950 \times 42$ & 58.0 & 118.5 & 3.56 & 523.4 & 417 & 397 & $1.63 \%$ & $1.72 \%$ & 1.05 & 0.95 \\
\hline SNSC6 & none & 23.0 & - & 13.2 & 523.4 & 305 & 260 & $1.33 \%$ & $1.06 \%$ & 1.17 & 1.26 \\
\hline SHSC7 & $575 \times 575 \times 42$ & 24.7 & 127.3 & 3.09 & 523.4 & 405 & 387 & $1.58 \%$ & $1.83 \%$ & 1.05 & 0.86 \\
\hline SHSC8 & $575 \times 575 \times 42$ & 38.9 & 125.2 & 3.19 & 532.3 & 428 & 394 & $1.60 \%$ & $1.77 \%$ & 1.09 & 0.90 \\
\hline SHSC9 & $950 \times 950 \times 42$ & 39.1 & 125.8 & 3.16 & 532.3 & 424 & 399 & $1.52 \%$ & $1.75 \%$ & 1.06 & 0.87 \\
\hline & & & & & & & & & Avg & 1.07 & 0.96 \\
\hline & & & & & & & & & COV & $4.59 \%$ & $12.99 \%$ \\
\hline
\end{tabular}

*Specimens investigated by Inácio et al. [17].

The theoretical predictions of the slab rotation at failure $\left(\psi_{\mathrm{th}}\right)$ are determined at the intersection between the failure criterion curve (equation (2)) and the load-rotation curve (equation (1)) for each specimen. The experimental slab rotations $\left(\psi_{\exp }\right)$ are derived from the 
vertical displacement measurements assuming a conical deformation of the slab outside the column region [39]. In particular the experimental rotations are calculated as $\psi_{\mathrm{th}}=v / \mathrm{r}$, where $v$ is the average vertical displacement in correspondence of the line of zero moments (see Figure 4) and $r$ is the distance of this line from the column (in this case $r=665 \mathrm{~mm}$ ).

The application of the CSCT shows good results in terms of punching capacity prediction. The average ratio between the experimental punching values and the theoretical predictions is equal to 1.07 while the coefficient of variation is $4.59 \%$. Furthermore, the average ratio between the experimental rotation at failure and the theoretical prediction is equal to 0.96 while the coefficient of variation is $12.99 \%$.

The application of the CSCT provides good results also for slabs with hybrid use of HSC. Considering only these specimens, the average ratio between the experimental punching values and the theoretical predictions is equal to 1.06 while the coefficient of variation is $1.44 \%$. The latter seems to confirm that the equivalence in terms of interlocking strength is correct and both equations (4) and (5) provide good results. Furthermore, the correction of the maximum aggregate size performed according to equation (3), in order to account the reduced roughness of the surface for high strength concrete, seems to lead to results on the safe side. For both the slab completely made of HSC and hybrid slabs the experimental punching loads are about $5 \%$ higher than the punching predictions.

\section{PARAMETRIC STUDY}

Therefore, according to the analytical approach shown above, a parametric analysis of the main variable affecting the performance of hybrid slabs is proposed. This analysis investigates the influence of both width and thickness of the HSC layer placed in hybrid slabs. A $200 \mathrm{~mm}$ thick slab with a span of $7.00 \mathrm{~m}$, supported by $400 \times 400 \mathrm{~mm}$ columns, is taken as case study. Eight hybrid slabs grouped in two series and one NSC slab are considered in this analysis. In the first series named "E" the HSC is extended to the entire slab surface while in the second series named " $R$ " the HSC is placed only near the column, allowing for a more rational use of this enhanced material. In this case the perimeter of the HSC layer is set at $2.0 \cdot \mathrm{h}$ from the column, that provides in this case a width of $1200 \mathrm{~mm}$. In both series four different thicknesses of HSC layer are simulated. In Figure 12 both series " $E$ " and " $R$ " are shown about their centreline. 


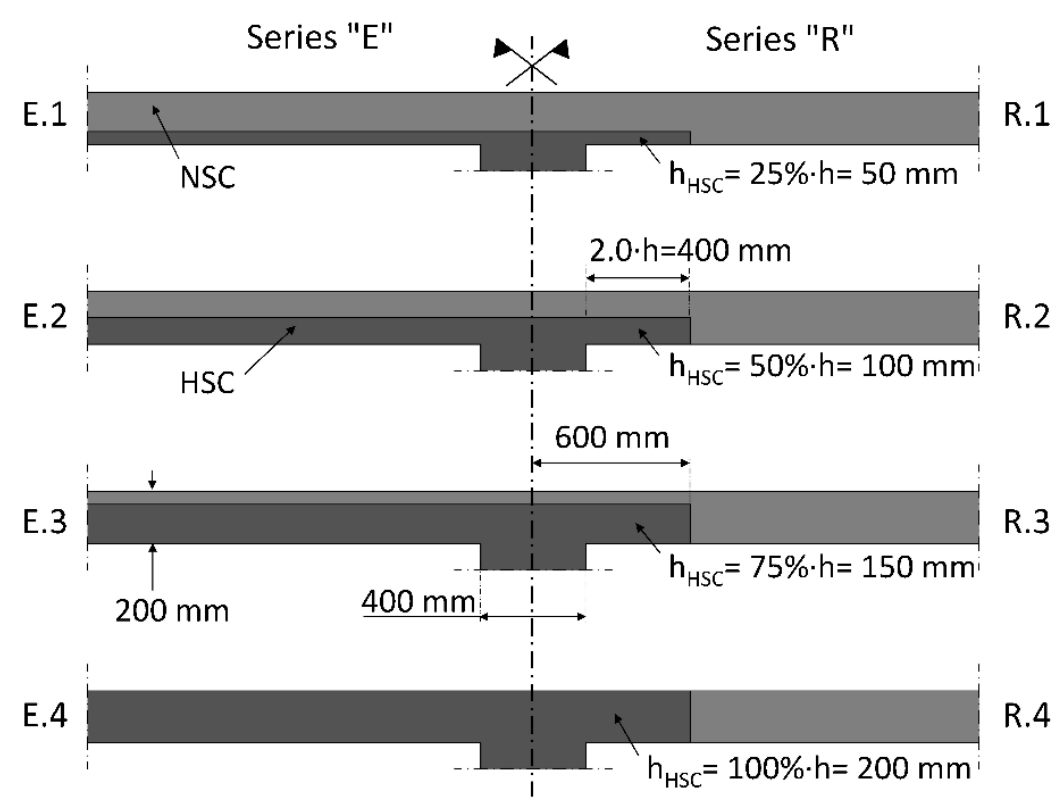

Figure 12 - Hybrid slabs: Series "E" and Series "R".

The concrete compressive strength of the NSC is chosen equal to $f_{C, N S C}=25 \mathrm{MPa}$, while the strength of the HSC is set equal to $\mathrm{f}_{\mathrm{C}, \mathrm{HSC}}=125 \mathrm{MPa}$. The maximum aggregate size is assumed equal to $\mathrm{d}_{\mathrm{g}}=16 \mathrm{~mm}$ for both NSC and HSC. The yielding of reinforcement is $\mathrm{f}_{\mathrm{y}}=450 \mathrm{MPa}$ and the longitudinal reinforcement ratio is taken equal to $\rho=1.25 \%$.

In Figure 13 and Figure 14 the results of the parametric analysis of the series " $E$ " and " $R$ " are shown respectively. The two series provide the same failure criterions but different loadrotation curves. In the series " $\mathrm{E}$ " the stiffer behavior of the hybrid slabs when compared to the reference slab made in NSC is quite evident. On the contrary the load-rotation curves provided by the series " $\mathrm{R}$ " appear very close to that of the reference slab. 


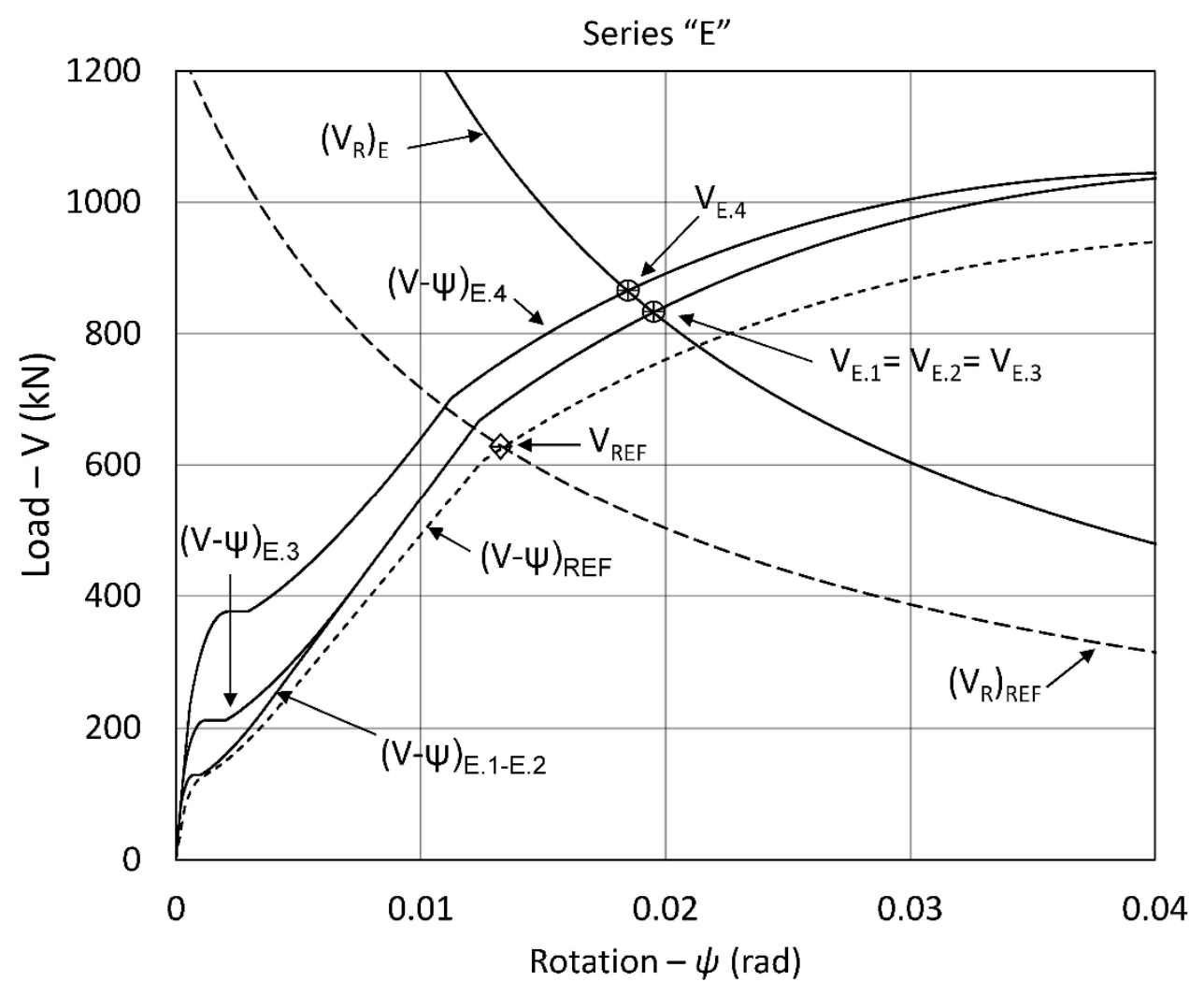

Figure 13 - Load-rotation curves and failure criterions: Parametric analysis Series "E".

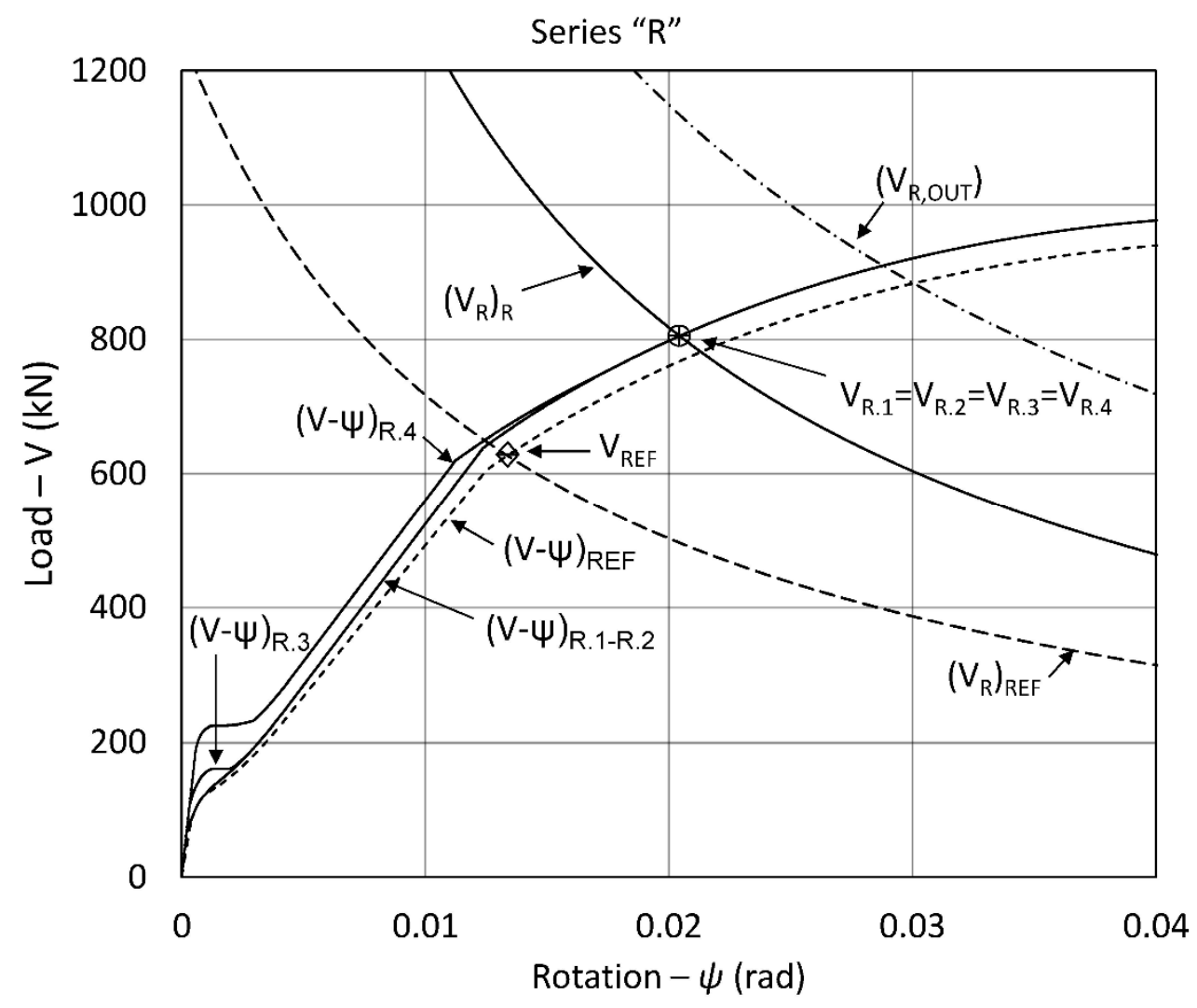

Figure 14 - Load-rotation curves and failure criterions: Parametric analysis Series " $\mathrm{R}$ ". 
For the slabs E.1(R.1) and E.2(R.2) the load-rotation curves $(\mathrm{V}-\Psi)$ are coincident, the cracking load results equal to that provided by the reference slab, while the flexural behaviour results stiffer than the latter. The increase in stiffness is more evident in the series " $E$ " than in the series "R". Slabs E.3(R.3) shows a higher cracking load, but at load increasing the load-rotation curve tends to overlap the curve provided by the first two hybrid slabs. Finally, the slabs E.4(R.4) provides the highest load-rotation curve when compared to the others. In general, from the comparison of load-rotation curves seems that in the series " $E$ " the use of more HSC leads to stiffer behaviour, while in the series " $R$ " the effect of using more HSC on the loadrotation curve is more subtle. The obtained results from slab E.4 completely made of HSC (Figure 13), that presented the stiffer behaviour, are in agreement with the experimental results shown in Figure 9, where also slab SHSC2 entirely casted with HSC, was more stiff than the other slabs partially made using HSC.

The theorical failure loads are higher on the hybrid slabs, when compared with the reference slab made completely out of NSC, also in agreement with the experimental results presented. However, the beneficial effects provided by the HSC are slightly more pronounced in the series " $E$ " than in the series " $R$ ". Actually, since in all cases the depth of the HSC layer is higher than the compressive depth, the slabs of both series have the same failure criterion. For this reason, the influence of increasing the thickness of the HSC resulted in very limited gains of load capacity. In the series " $R$ " there are no difference between the failure loads provided by the hybrid slabs when changing the thickness of the HSC zone, while in the series "E" the slab E.4 gives slightly higher punching strength when compared to the other. The latter confirms the experimental evidences discussed above. This observation seems to suggest that the optimal thickness for the HSC zone should be higher than the compressive depth, but not more.

The results of the analysis are listed in Table 7.

Table 7 - Parametric analysis of hybrid slabs according to the analytical approach.

\begin{tabular}{|c|c|c|c|c|c|c|c|c|c|c|c|}
\hline \multirow{2}{*}{ Specimen } & \multicolumn{3}{|c|}{ HSC layer } & \multirow{2}{*}{$\begin{array}{c}\mathrm{d} \\
(\mathrm{mm})\end{array}$} & \multirow{2}{*}{$\begin{array}{c}\rho \\
(\%)\end{array}$} & \multicolumn{2}{|c|}{$\mathrm{f}_{\mathrm{c}}(\mathrm{MPa})$} & \multirow{2}{*}{$\begin{array}{l}d_{g, e q} \\
(m m)\end{array}$} & \multirow{2}{*}{$\begin{array}{c}f_{y} \\
\text { (MPa) }\end{array}$} & \multicolumn{2}{|c|}{$\begin{array}{l}\text { Punching } \\
\text { strength }\end{array}$} \\
\hline & $\begin{array}{l}\text { Width } \\
\text { (mm) }\end{array}$ & $\begin{array}{l}\text { Depth } \\
(\mathrm{mm})\end{array}$ & $\begin{array}{c}\text { Volume** } \\
\text { (\%) }\end{array}$ & & & NSC & HSC & & & $\begin{array}{l}V_{\text {th }} \\
(k N)\end{array}$ & $\begin{array}{l}\Delta \mathrm{V}^{*} \\
(\%)\end{array}$ \\
\hline REF & - & - & - & 159 & 1.25 & 25 & - & 16 & 450 & 627 & - \\
\hline E.1 & Full & 50 & $25 \%$ & 159 & 1.25 & 25 & 125 & 3.69 & 450 & 832 & $+33 \%$ \\
\hline E.2 & Full & 100 & $50 \%$ & 159 & 1.25 & 25 & 125 & 3.69 & 450 & 832 & $+33 \%$ \\
\hline E.3 & Full & 150 & $75 \%$ & 159 & 1.25 & 25 & 125 & 3.69 & 450 & 832 & $+33 \%$ \\
\hline E.4 & Full & 200 & $100 \%$ & 159 & 1.25 & - & 125 & 3.69 & 450 & 865 & $+38 \%$ \\
\hline R.1 & 1200 & 50 & $0.73 \%$ & 159 & 1.25 & 25 & 125 & 3.69 & 450 & 805 & $+28 \%$ \\
\hline R.2 & 1200 & 100 & $1.47 \%$ & 159 & 1.25 & 25 & 125 & 3.69 & 450 & 805 & $+28 \%$ \\
\hline R.3 & 1200 & 150 & $2.20 \%$ & 159 & 1.25 & 25 & 125 & 3.69 & 450 & 805 & $+28 \%$ \\
\hline R.4 & 1200 & 200 & $2.94 \%$ & 159 & 1.25 & 25 & 125 & 3.69 & 450 & 805 & $+28 \%$ \\
\hline
\end{tabular}

*Increase in punching strength calculated with respect to the reference slab

**HSC volume to total slab volume ratio

Comparing the results obtained by the two series arises that the width of the HSC layer has a small influence in the punching strength. Indeed, the failure loads provided by the two series are very close. Actually the width of the HSC layer comes into play when the failure surface develops outside the strengthened zone affecting only the NSC [22]. This scenario could be easily accounted calculating both the failure criterions inside $\left(V_{R}\right)$ and outside $\left(V_{R, O U T}\right)$ the strengthened zone (see Figure 14). In this case the failure criterion outside the strengthened zone resulted always higher than the others, therefore this failure was avoided. 
Besides the series " $R$ " gets a very small amount of HSC (about $3 \%$ of the series " $E$ ") the increase in punching strength, calculated with respect to the reference slab, resulted very close to that provided by the series " $E$ ".

(a)

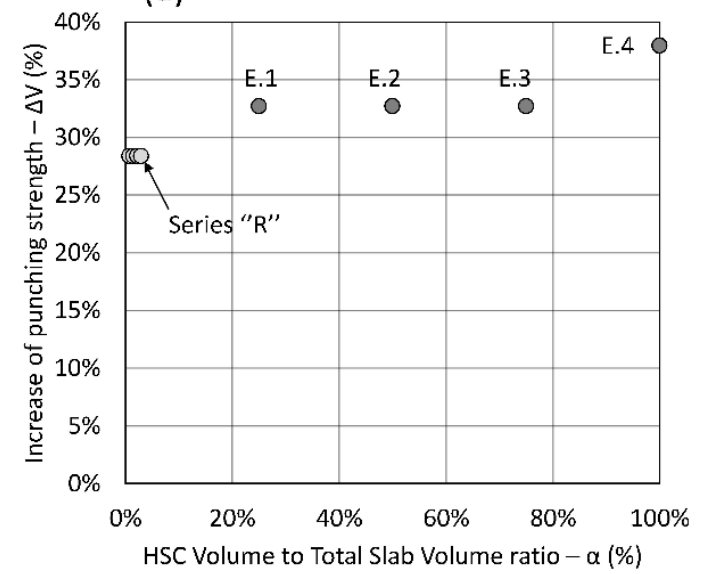

(b)

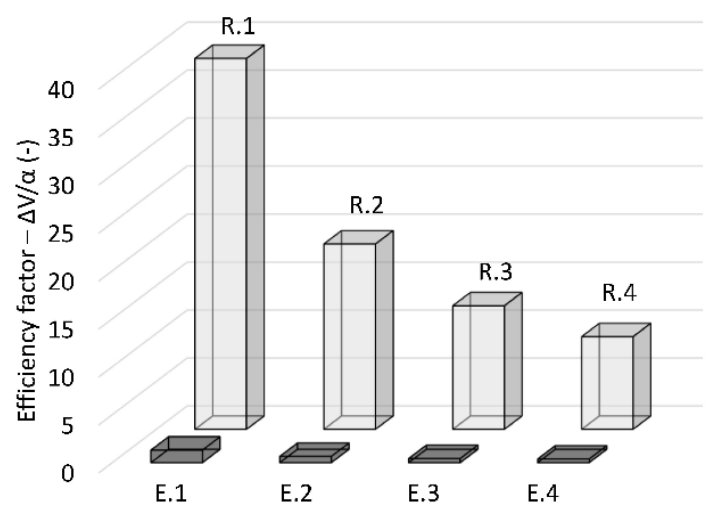

Figure 15 - Parametric analysis: (a) Relationship between the increase of punching strength and the HSC use (b) Efficiency factor defined as the ratio between the increase in punching strength and the use of HSC.

In Figure 15 (a) the relationship between the increase of punching strength, with respect to the reference slab, and the HSC volume to the total slab volume ratio is shown for both series. It is evident that a rational use of the HSC provides excellent results in terms of increase in punching strength and allows for saving material. This result is highlighted in Figure 15 (b), where the efficiency factor, defined as the ratio between the increase of punching strength (\%) and the volume of HSC (\%), is provided. R.1 is the most efficient configuration providing an efficiency factor equal to $E F=39$. Indeed, according to this configuration, that uses only $0.73 \%$ volume of HSC, it is possible to increase the punching strength up to $28 \%$. In Figure 16 the influence of the longitudinal reinforcement ratio $(\rho)$ is also investigated. The longitudinal reinforcement ratio is varied from $0.75 \%$ to $1.75 \%(\rho=0.75 \%, \rho=1.00 \%, \rho=1.25 \%, \rho=1.50 \%$, $\rho=1.75 \%)$ while the other characteristics are kept unchanged from the previous analysis ( $L=7$ $\mathrm{m}, \mathrm{H}=200 \mathrm{~mm}, \mathrm{~d}=159 \mathrm{~mm}, \mathrm{f}_{\mathrm{c}, \mathrm{NSC}}=25 \mathrm{MPa}, \mathrm{f}_{\mathrm{c}, \mathrm{HSC}}=125 \mathrm{MPa}, \mathrm{f}_{\mathrm{y}}=450 \mathrm{Mpa}, \mathrm{d}_{\mathrm{g}}=16 \mathrm{~mm}$ ).

(a)

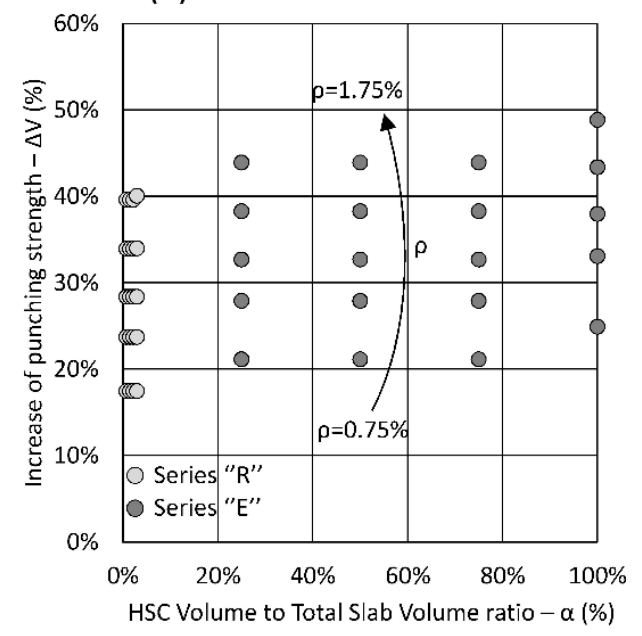

(b)

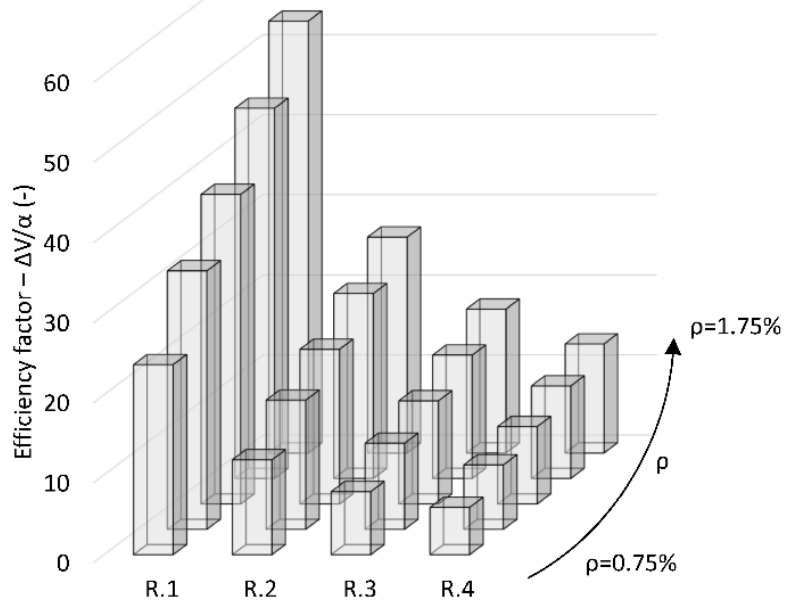


Figure 16 - Parametric analysis: (a) Relationship between the increase of punching strength and the HSC use, at varying of the longitudinal reinforcement ratio (b) Efficiency factor for the series " $R$ " at varying of the longitudinal reinforcement ratio.

In Figure 16 (a) the relationship between the increase of punching strength, with respect to the reference slab, and the HSC volume to the total slab volume ratio is shown for both series "E" and " $\mathrm{R}$ " at varying of the longitudinal reinforcement ratio. The beneficial effect provided using HSC is highly affected by longitudinal reinforcement ratio: at longitudinal reinforcement ratio increasing the beneficial effect provided by the HSC increases too. In Figure 16 (b), the efficiency factor for the series " $\mathrm{R}$ " at varying the longitudinal reinforcement ratio is provided. According to this analysis the most efficient configuration is R.1 that provides an efficiency factor equal to $E F=54$ for $\rho=1.75 \%, E F=46$ for $\rho=1.50 \%, E F=39$ for $\rho=1.25 \%, E F=32$ for $\rho=1.00 \%$ and $E F=24$ for $\rho=0.75 \%$.

Finally, the influence of the span to depth ratio $(\mathrm{L} / \mathrm{H})$ is also investigated (Figure 17). The longitudinal reinforcement ratio is assumed equal to $\rho=1.25 \%$, the span to depth ratio $(L / H)$ is varied from 25 to $45(\mathrm{~L} / \mathrm{H}=25, \mathrm{~L} / \mathrm{H}=30, \mathrm{~L} / \mathrm{H}=35, \mathrm{~L} / \mathrm{H}=40, \mathrm{~L} / \mathrm{H}=45)$ while the other characteristics are kept unchanged from the first analysis $\left(H=200 \mathrm{~mm}, d=159 \mathrm{~mm}, \mathrm{f}_{\mathrm{C}, \mathrm{NSC}}=25 \mathrm{MPa}, \mathrm{f}_{\mathrm{C}, \mathrm{HSC}}=125\right.$ MPa, $f_{y}=450 \mathrm{Mpa}, d_{g}=16 \mathrm{~mm}$ ).

(a)

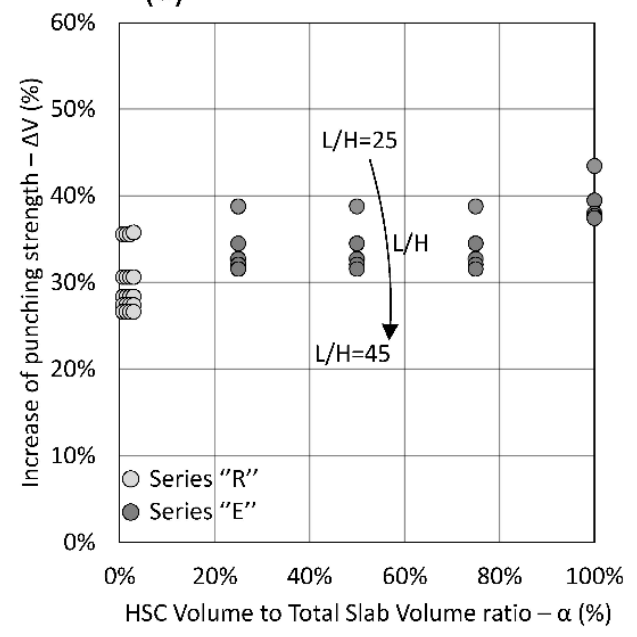

(b)

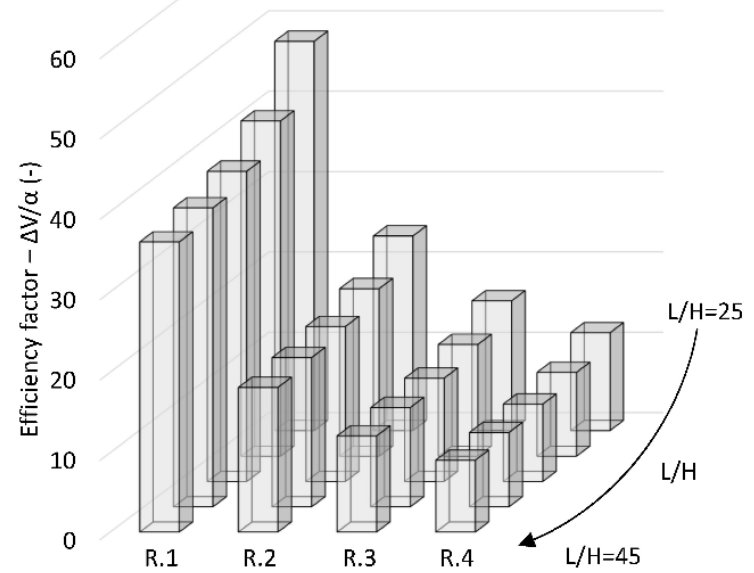

Figure 17 - Parametric analysis: (a) Relationship between the increase of punching strength and the HSC use, at varying of the span to depth ratio (b) Efficiency factor for the series " $R$ " at varying of the span to depth ratio.

The span to depth ratio $(\mathrm{L} / \mathrm{H})$ has a low influence on the effectiveness provided by the partial use of HSC. At the span to depth ratio increasing the beneficial effect provided by the HSC decreases. However, the efficiency factors achieved with different span to depth ratios are very close to each other. The series R.1 provides an efficiency factor equal to $E F=48 \mathrm{for} H / L=25$, $E F=42$ for $H / L=30, E F=39$ for $H / L=35, E F=37$ for $H / L=40$ and $E F=36$ for $H / L=55$.

In general, the beneficial effect provided by the HSC increases for flexural stiffness increasing. The latter increases for longitudinal reinforcement ratio increasing or for span to depth ratio decreasing. However, the influence of the longitudinal reinforcement ratio is much more pronounced than that provided by the span to depth ratio.

Therefore, for a rational use of the HSC in RC slabs, the configuration with HSC placed only near the column in compression zone is suggested. The width of the HSC layer should be 
determined in order to avoid the failure outside the strengthened zone. However, a minimum distance of the HSC layer's perimeter from the column should be considered. To avoid this possibility a minimum distance of $2 \cdot \mathrm{h}$ from the column, as adopted in the series " $\mathrm{R}$ ", is suggested. The thickness of the HSC layer should be determined according to the compressive depth, however a minimum thickness is required for constructive reasons. From a constructive point of view $50 \mathrm{~mm}$ could be considered the minimum thickness for pouring.

\section{CONCLUSIONS}

This paper deals with punching of reinforced HSC flat slabs, with emphasis on the rational use of this enhanced material. Four slab specimens with HSC and one made of NSC were tested under monotonic vertical loading. The HSC was placed only in slab column region and it was limited to a thin layer in the slab's compressive zone. This rational use of the HSC showed excellent results in terms of increasing the punching strength. Limiting the HSC to a thin layer in the compressive zone, the punching strength resulted almost equal to that obtained with the slab entirely casted in HSC.

The application of the CSCT to slabs with partial use of HSC was presented and discussed. This application accounts for the modifications, provided by the presence of the HSC, in both the load-rotation curve and in the failure criterion. The possibility, for high-strength concrete members, to develop cracks passing through the aggregate rather than passing around them is also accounted: the maximum aggregate size is corrected accounting for the reduced roughness of the failure surface.

The extended analytical approach showed good results in terms of failure load prediction. The average ratio between the experimental punching value and the theoretical prediction of the hybrid slabs resulted equal to 1.07 while the coefficient of variation resulted in $4.59 \%$. These results seem to confirm that the proposed approach is correct. However, for a full validation of the method further tests with different thicknesses of the HSC layer are recommended. In particular, the contribution in terms of shear strength of the concrete outside the compression zone should be investigated deeper.

Finally, to extend the results of the experimental campaign a parametric analysis was performed. This analysis investigated the influence of both width and thickness of the HSC layer in hybrid slabs. Two configurations were examined, one with the HSC layer extended to the whole slab's surface and the other with the HSC limited near the column. The second configuration was much more efficient than the use of HSC on the whole slab, using fewer amounts of HSC and achieving almost the same behaviour and punching strength capacity. This way the economic impact of using HSC was minimized, enhancing its competitiveness.

\section{ACKNOWLEDGEMENTS}

This work received support from the Fundação para a Ciência e Tecnologia - Ministério da Ciência, Tecnologia e Ensino Superior through projects EXPL/ECM - EST/1371/2013 and PTDC/ECI-EST/30511/2017 and scholarship number SFRH/BD/76242/2011. The authors are 
grateful to CIMPOR for providing the cement and Sika for providing VISCOCRETE 2OHE and SIKACRETE HD.

\section{REFERENCES}

[1] Guo, S.; Tsai, T.; Application of High Performance Concrete on a 85-story High Rise Building in Taiwan, 13th Symposium of International Association for Automation and Robotics in Construction, 1997: pp. 933-40.

[2] Aitcin, P-C.; High Performance Concrete: modern concrete technology 5, New York: CRC press; 2004.

[3] Kawai, T.; State of the art report on high strength concrete in Japan-recent developments and applications. Jt. Semin. Concr. Eng. Vietnam Work., 2005, p. 87-107.

[4] Waleed, N.; High strength concrete in bridge construction : a state-of-the-art report, Camberley: Concrete Bridge Development Group, Concrete Society; 2005.

[5] Baker, WF.; James, P.; Tomlinson, R.; Weiss, A.; Case Study: Trump International Hotel \& Tower, CTBUH Journal, 2009: pp. 16-22.

[6] Howard, NL.; Leatham, DM.; Production and Delivery of High-Strength Concrete, Concrete International, 1989, Vol. 11: pp. 26-30.

[7] Caldarone, MA.; High-strength Concrete A pratical guide, London and New York: Taylor \& Francis; 1994.

[8] $\mathrm{ACl}$ Committee 363.; Report on High-Strength Concrete ( $\mathrm{ACl}$ 363R-10), Farmington Hills, U.S.A.: ACl; 2010.

[9] Inácio, M.; Comportamento ao Punçoamento de Lajes Fungiformes em Betão de Elevada Resistência. FCT-UNL New University of Lisbon, 2014.

[10] American Concrete Institute.; Building Code Requirements for Structural Concrete (ACl 318-19), 2019.

[11] CEN.; Eurocode 2: Design of concrete structures - Part 1-1: General rules and rules for buildings, Bruxelles: 2004.

[12] CEB/FIP.; Model Code 2010 - Volume 1, Bulletin 6, Lausanne, Switzerland: Internation Federation for Structural Concrete (fib); 2012.

[13] Marzouk, H.; A. Hussein.; Experimental Investigation on the Behavior of HighStrength Concrete Slabs, ACI Structural Journal, 1991, Vol. 88: pp. 701-13.

[14] Regan, PE.; Al-Hussaini, A.; Ramdane, K-E.; Xue, H-Y.; Behaviour of High Strength Concrete Slabs. In: Dhir RK, Jones RM, editors. Concr. 2000 - Econ. durable Constr. through Excell., Dundee, Scotland: E \& FN Spon; 1993, p. 761-73.

[15] Ramdane, KE.; Punching Shear of High Performance Concerte Slabs. 4th Int. Symp. Util. High-Strength/High-Performance Concr., Paris: 1996, p. 1015-26.

[16] Tomaszewicz, A.; High Strength Concrete: SP2 - Plates and Shells Report 2.3. Punching Shear Capacity of Reinforced Concrete Slabs, Oslo, Norway: 1993.

[17] Inácio, MMG.; Almeida, AFO.; Faria, DMV.; Lúcio, VJG.; Ramos, AP.; Punching of high strength concrete flat slabs without shear reinforcement, Engineering Structures, 2015, Vol. 103: pp. 275-84.

[18] Faria, DMV.; Biscaia, H.; Lucio, VJG.; Ramos, APA.; Material and Geometrical Parameters Affecting Punching of Reinforced Concrete Flat Slabs. fib Symp. 2011 - Concr. Eng. Excell. Effic., Prague: 2011.

[19] Mamede, N.; Ramos, A.; Faria, D.; Experimental and Parametric 3D Nonlinear 
Finite Element Analysis on Punching of Flat Slabs with Orthogonal Reinforcement, Engineering Structures, 2013, Vol. 48: pp. 442-57.

[20] Hallgren, M.; Punching Shear Capacity of Reinforced High Strength Concrete Slabs. Royal Institute of Technology, Stockholm, Sweden, 1996.

[21] Hallgren, M.; Kinnunen, S.; Increase of Punching Shear Capacity by Using High Strength Concrete. 4th Int. Symp. Util. High-Strength/High-Performance Concr., 1996, p. 1037-46.

[22] Zohrevand, P.; Yang, X.; Jiao, X.; Mirmiran, A.; Punching Shear Enhancement of Flat Slabs with Partial Use of Ultrahigh-Performance Concrete, Journal of Materials in Civil Engineering, 2015, Vol. 27: pp. 1-10.

[23] Duval, R.; Kadri, EH.; Influence of silica fume on the workability and the compressive strength of high-performance concretes, Cement and Concrete Research, 1998, Vol. 28: pp. 533-47.

[24] Igarashi, SI.; Watanabe, A.; Kawamura, M.; Evaluation of capillary pore size characteristics in high-strength concrete at early ages, Cement and Concrete Research, 2005, Vol. 35: pp. 513-9.

[25] Bhanja, S.; Sengupta, B.; Influence of silica fume on the tensile strength of concrete, Cement and Concrete Research, 2005, Vol. 35: pp. 743-7.

[26] Siddique, R.; Utilization of silica fume in concrete: Review of hardened properties, Resources, Conservation and Recycling, 2011, Vol. 55: pp. 923-32.

[27] CEN.; EN 12390-3 Testing hardened concrete Part 3: Compressive strength of test specimens, Bruxelles: 2001.

[28] CEN.; EN 12390-6 Testing hardened concrete Part 6: Tensile splitting strength of test specimens, Bruxelles: 2000.

[29] CEN.; EN 12390-13 Testing hardened concrete Part 13: Determination of secant modulus of elasticity in compression, Bruxelles: 2013.

[30] CEN.; EN 10002-1 Metallic materials Tensile testing Part 1: method of test at ambient temperature, Bruxelles: 2001.

[31] Bompa, D V.; Onet, T.; Punching shear strength of RC flat slabs at interior connections to columns, Magazine of Concrete Research, 2016, Vol. 68: pp. 2442.

[32] Muttoni, A.; Punching shear strength of reinforced concrete slabs without transverse reinforcement, ACI Structural Journal, 2008, Vol. 105: pp. 440-50.

[33] Lapi, M.; Fernandes, H.; Orlando, M.; Ramos, AP.; Lucio, VJG.; Performance assessment of flat slabs strengthened with a bonded reinforced concrete overlay, Magazine of Concrete Research, 2017.

[34] Vecchio, FJ.; Collins, MP.; The modified compression-field theory for reinforced concrete elements subjected to shear, ACl Journal Proceedings, 1986, Vol. 83: pp. 219-31.

[35] Bentz, EC.; Vecchio, FJ.; Collins, MP.; Simplified Modified Compression Field Theory for Calculating Shear Strength of Reinforced Concrete Elements, $\mathrm{ACl}$ Structural Journal, 2006, Vol. 103: pp. 614-24.

[36] Muttoni, A.; Fernández Ruiz, M.; Simões, JT.; The theoretical principles of the critical shear crack theory for punching shear failures and derivation of consistent closed-form design expressions, Structural Concrete, 2017, Vol. 19: pp. 1-17.

[37] Inácio, MMG.; PhD Thesis - Comportamento ao Punçoamento de Lajes 
Fungiformes em Betão de Elevada Resistência. Universidade Nova de Lisboa, 2016.

[38] Simões, JT.; Faria, DM V.; Ruiz, MF.; Muttoni, A.; Strength of reinforced concrete footings without transverse reinforcement according to limit analysis, Engineering Structures, 2016, Vol. 112: pp. 146-61.

[39] Lapi, M.; Ramos, AP.; Orlando, M.; Flat slab strengthening techniques against punching-shear, Engineering Structures, 2019, Vol. 180: pp. 160-80. 